
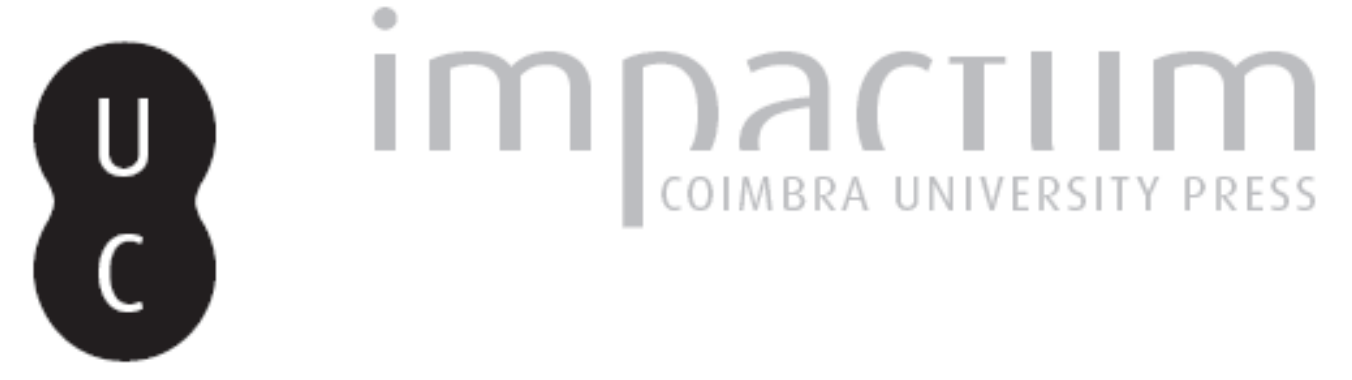

\title{
La recepción de "Annales" en España: las reuniones de metodología histórica de 1973 y 1982: para una metodología aplicada a la historia social
}

\author{
Autor(es): $\quad$ Eiras Roel, Antonio \\ Publicado por: Centro de História da Sociedade e da Cultura \\ URL \\ persistente: \\ URI:http://hdl.handle.net/10316.2/39383 \\ DOI: \\ DOI:http://dx.doi.org/10.14195/1645-2259_13_1 \\ Accessed : $\quad$ 26-Apr-2023 16:18:14
}

A navegação consulta e descarregamento dos títulos inseridos nas Bibliotecas Digitais UC Digitalis, UC Pombalina e UC Impactum, pressupõem a aceitação plena e sem reservas dos Termos e Condições de Uso destas Bibliotecas Digitais, disponíveis em https://digitalis.uc.pt/pt-pt/termos.

Conforme exposto nos referidos Termos e Condições de Uso, o descarregamento de títulos de acesso restrito requer uma licença válida de autorização devendo o utilizador aceder ao(s) documento(s) a partir de um endereço de IP da instituição detentora da supramencionada licença.

Ao utilizador é apenas permitido o descarregamento para uso pessoal, pelo que o emprego do(s) título(s) descarregado(s) para outro fim, designadamente comercial, carece de autorização do respetivo autor ou editor da obra.

Na medida em que todas as obras da UC Digitalis se encontram protegidas pelo Código do Direito de Autor e Direitos Conexos e demais legislação aplicável, toda a cópia, parcial ou total, deste documento, nos casos em que é legalmente admitida, deverá conter ou fazer-se acompanhar por este aviso.

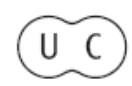



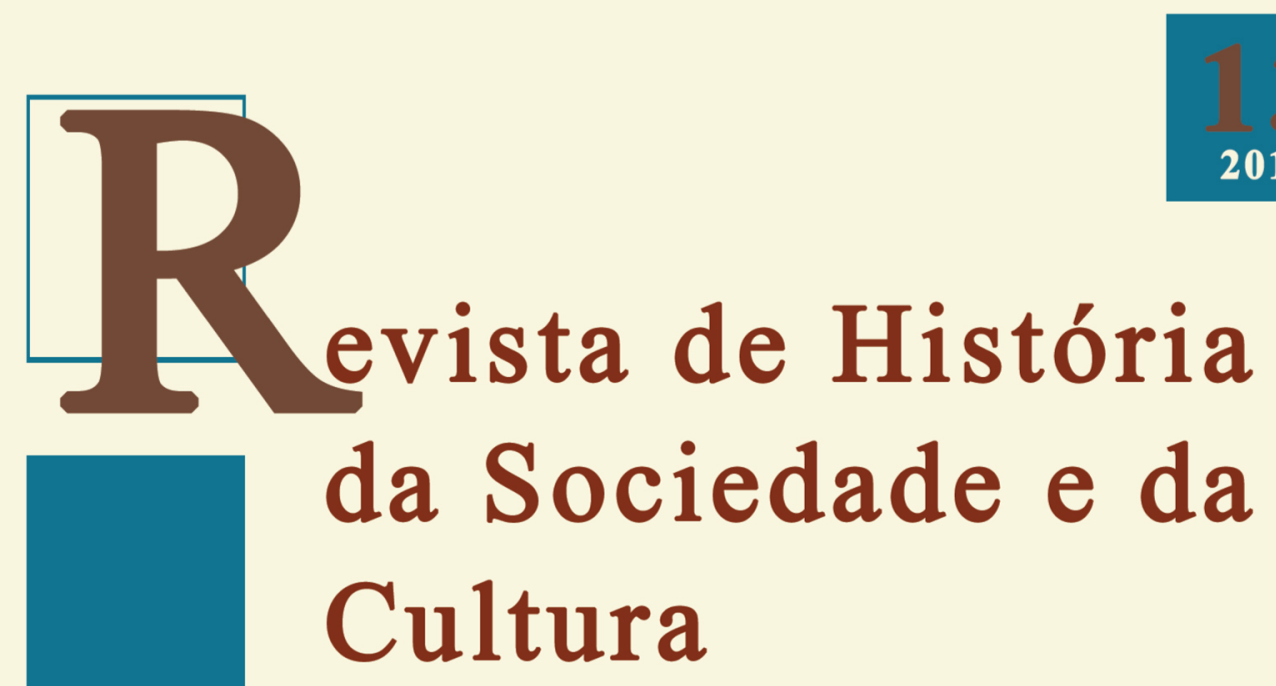

2013

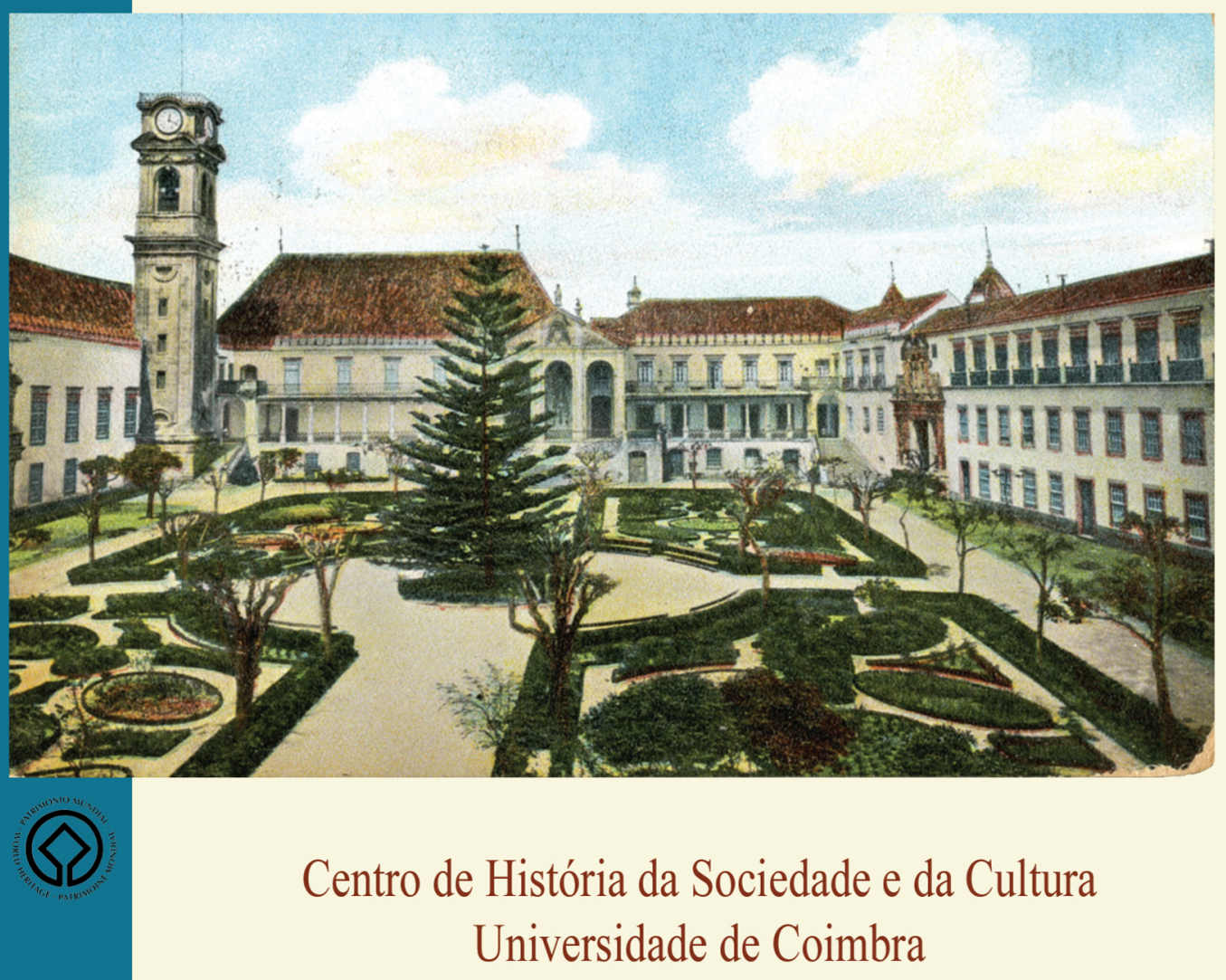

Coimbra 


\title{
La recepción de "Annales" en España: las reuniones de metodología histórica de 1973 y 1982. Para una metodología aplicada a la historia social
}

\author{
Antonio Eiras Roel \\ Catedrático Emérito de Historia Moderna - Univ. Santiago de Compostela \\ aaeiras@telefonica.et \\ Texto recebido em /Text submitted on: 31/05/2013 \\ Texto aprovado em /Text approved on: 12/07/2013
}

\section{Resumo/Abstract:}

1. El punto de partida: el cuartel de invierno de la historiografía alemana.

2. El influjo directo. Las revistas francesas y el movimiento editorial de los años 60 .

3. De Leningrado a Compostela. Las Jornadas de 1973, antecedentes y continuidad (1982).

4. Las ideas directrices: Labrousse, Goubert, Le Roy Ladurie y otros guías.

1 - Labrouse. 2 - Goubert. 3 - Le Roy Ladurie.

5. Del documento notarial a la historia social: el segundo coloquio europeo de 1982.

6. Propuesta, a modo de reflexión final. ¿Hacia una historia comparada?

1. The starting point: the headquartes of Germanic erudition.

2. The direct influence: French reviews and publishing avalanche in the sixtieths.

3. The turning point: from the international congress of Leningrad 1970 to the Jornadas 1973.

4. Ideal lines of force: Labrousse, Goubert, Le Roy Ladurie among the main guides.

5. Notarial source and social history: the european meeting in Compostela 1982.

6. A final reflection: comparative history as a proposal.

Palavras chave/Keywords:

Historia social; Historia comparada; Metodología; "Annales”; Labrousse; Goubert; Le Roy Ladurie.

Social history; Comparative history; Methodology; "Annales"; Labrousse; Goubert; Le Roy Ladurie. 


\section{Proemio}

Las páginas que siguen, según su título dedicadas a glosar retrospectivamente unos encuentros científicos que se celebraron en territorio peninsular hace cuarenta años (en 1973 y luego en 1982), tienen en realidad la pretensión de recordar y revivir una metodología histórica nueva por entonces, cuyas líneas directrices se tomaban directamente de la corriente de escuela entonces hegemónica y todavía presente y actuante en la historia social y en muchos de nosotros. En su momento de mayor esplendor esa metodología histórica produjo obras de referencia dignas de ser emuladas, admirables por su número y calidad, de entre las cuales las aquí comentadas son sólo algunas muestras, aunque muy importantes; por lo que a nuestro entender esa corriente de escuela se reveló eficaz y su metodología histórica merece ser preservada.

Los encuentros que dan título a este trabajo surgieron en virtud de motivaciones espontáneas que provocaba por aquellos años la novedad de las monografías y la fuerza de las ideas directrices que encontrábamos en ellas y en multitud de trabajos publicados en las Revistas, principalmente de Francia. A esas ideas directrices y líneas de trabajo dedicaremos la parte central y substancial de esta exposición, sintetizada en un corto número de obras y de autores de particular relevancia, que trataremos de presentar ordenadamente.

Pretendemos explicar cómo se gestaron aquellos decisivos encuentros y exponer la génesis que les da sentido y contenido, a partir de las motivaciones bibliográficas que nos llegaban del país vecino y de algunos contados encuentros exteriores vividos en los congresos internacionales de historia y de historia económica que tuvieron lugar en los años inmediatamente anteriores, a los que necesariamente hemos de referirnos. Pensamos por otra parte que aquellas influencias no eran privativas de un determinado lugar y que esos mismos influjos llegaban simultáneamente a las Universidades portuguesas y a otras por los mismos canales de libros y revistas procedentes de toda Europa y en especial de Francia, con la que no existían barreras idiomáticas. ${ }^{1}$

1 Nos consta que las influencias europeas y el clima intelectual de aquel fructífero momento de renovada apertura al exterior tuvieron igual acogida en Universidades 
La hegemonía de la escuela de Annales ha pasado y ha dejado paso en nuestros días a otras tendencias más pluralistas, en donde encuentran su espacio tanto otros influjos de un exterior hoy globalizado como la recuperación de temáticas específicas de la tradición historiográfica de cada país. Eso no puede significar que haya pasado en vano: lo que hoy sabemos sobre la historia social de la Europa moderna, y el modo cómo lo conocemos, se debe en buena parte - ¿tal vez en su mayor parte? - al aporte y al influjo de aquella generación de historiadores de las décadas centrales del pasado siglo y a las cohortes sucesivas de seguidores de la misma escuela dentro y fuera de Francia; por eso decimos que en nuestro sentir la corriente merece ser preservada. Este es un concepto en el que se debe insistir, por el valor decisivo y necesario de las aportaciones de aquella generación o generaciones. Sobre ese punto el mensaje de este trabajo desea ser claro: la parte de la tarea que cupo a la generación de los sesenta (sobre todo en Francia) no puede ser ignorada. Dondequiera que esa tarea esté a medio realizar será necesario completarla para seguir avanzando, si se quiere pisar sobre terreno firme.

Aquellos encuentros reunidos en esos años $-\mathrm{y}$ otros posteriores, tal vez más modestos pero no diferentemente orientados - encontraron amplia acogida entre los jóvenes historiadores españoles o peninsulares de aquel momento, síntoma de los anhelos de renovación que entonces se vivían. Un examen de la situación de la historiografía en la península ibérica

portuguesas como la de Coimbra, con cuyo Instituto de História Económica e Social manteníamos ya entonces (años 1968 y siguientes) una fructífera relación de intercambio, a través de los profesores Luis Ferrand de Almeida y António de Oliveira y de varios de sus discípulos y colaboradores en ese instituto. Algunos profesores eminienses de aquellos años participaban de la misma corriente en grados bien perceptibles. Desde 1962 al menos, los trabajos de Ferrand Almeida (RPH, X (1962) 203-242; RPH, XV (1975) 339-420; RPH, XXVII (1992) 103-143) obedecen a ese influjo contextual y referencial, patente tanto en la temática como en las conexiones bibliográficas; y lo mismo cabe decir en tema y desarrollo de la tesis de António de Oliveira, A vida económica e social de Coimbra de 1537 a 1640, Coimbra, 1972, libro de inspiración braudeliana en los capítulos dedicados al artesanado y civilización material, comercio y crédito, alimentación y abasto urbano; y con otras influencias de la historiografía reciente en los capítulos dedicados a las innovaciones agrarias (el maíz, en ambos casos). En los numerosos trabajos de los dos autores citados sobre la conflictividad social y motines populares en el Portugal del XVII son patentes las conexiones con las obras de Mousnier (Calmann-Lévy, 1967) y de Porschnev (SEVPEN, 1963) así como el famoso debate entre ambos autores. 
(o más concretamente en España) hace cuatro décadas y los nuevos rumbos emprendidos por entonces en algunas "periferias" peninsulares, además de servir para examinar lo que desde entonces se hizo realidad y lo que sigue pendiente, puede ser también de utilidad para considerar (o reconsiderar) los cambios de rumbo que desde entonces se han producido. Ambas cosas sumadas debieran contribuir a suscitar la discusión actualmente indispensable sobre los problemas que afectan a la historiografía española, peninsular y europea, en lo que ha dado en llamarse la crisis de la historia.

Es evidente, el asunto que aquí se trata forma parte de ese gran movimiento de renovación historiográfica que en aquellas décadas alcanzó a toda Europa bajo forma de difusión de la historiografía francesa del momento: la segunda generación de Annales. En esa órbita y contexto generacional fueron convocadas las Jornadas de Metodología Histórica de abril de 1973, a las que seguiría un segundo coloquio de análogo carácter en septiembre de 1982, ambos en Compostela. Su espíritu, más que ruptura con lo anterior, ampliación de espacios en todos los sentidos. Sus resultados en orden a la investigación, cien trabajos publicados en los tres volúmenes de Actas de aquellos dos encuentros, distribuidos en cuatro secciones monográficas: historia rural, demografía histórica, historia coyuntural, relaciones mercantiles. El denominador común entre ambos coloquios era el mismo que pretende dar sentido y unidad a esta exposición: problemas, fuentes y métodos para una ampliación temática de la disciplina. Esto es, directrices para una metodología de la historia social: nuevos objetos de estudio progresivamente ampliados, nuevos métodos mejor formalizados, nuevas fuentes no intencionales específicas de esa dimensión de la historia. ${ }^{2}$

Dos menudos évenements guardan relación próxima con la génesis de aquellos encuentros y con la elección o designación de los ponentes o cabezas de serie que aportaron algunas de las ideas rectoras, por lo que no puede excursarse su mención. El primero fue la asistencia de la persona encargada de organizar aquellos eventos a dos importantes congresos celebrados en

2 Cf. Actas 1973 y Actas 1982. Se nos permitirá de todos modos que no intentemos desarrollar detalladamente ese triple aporte en los reducidos límites de este texto. Sobre los tres elementos configuradores de la nueva metodología de la historia-problema, remitimos a nuestra introducción al volumen colectivo Las Fuentes y los Métodos, 1977, "Problemas, fuentes y métodos para una Historia", p. 7-23. 
1970, que aportaron resultados sobre los que habrá que volver. El segundo sería el acuerdo adoptado dos años más tarde por la Facultad de Historia compostelana de conmemorar el cincuentenario de su fundación (en 1923) con un congreso científico cuya organización le fue encomendada a la misma persona. Los fastos de esa celebración iban a brindar la oportunidad que se necesitaba para reunir en Compostela a las cabezas de la renovación metodológica de la historia social en aquel momento: Labrousse, Goubert, Le Roy Ladurie, entre otros. A ellos dedicaremos la parte central y esencial de nuestro análisis. ${ }^{3}$

\section{El punto de partida: el cuartel de invierno de la historiografía alemana}

El espacio reservado a este texto debe ser dedicado a los cambios que se producían en la historiografía hace cuarenta años, y en los años previos a la fecha de 1973 que motiva el tema. Pero visualizar el cambio requiere contar con dos referentes, el antes y el después. Eso nos lleva a comenzar por una mención rápida del tipo de formación que recibían los estudiantes españoles que se licenciaban en historia a mediados del pasado siglo (en 1954, el autor de este comentario).

La huella que se recibía de los profesores mejor formados de aquella época, los libros en que se bebía y los autores de los que se oía hablar, venían todos de la historiografía alemana del siglo XIX (Ranke, Mommsen, Burckhardt, con su prolongación en los Weber, Sombart, Haebler, Walter Goetz, Ernst Mayer, etc.), así como de sus competentes discípulos españoles (Eduardo de Hinojosa, Rafael Altamira, Eduardo Ibarra, Ballesteros Beretta, Ramón Menéndez Pidal, García de Valdeavellano), portugueses, etc.

3 A ciencia cierta, y sin desmerecer el valor de las relaciones personales que depararon, el mayor provecho de aquel viaje de 1970 serían los congresos mismos, por el contenido de sus temas y el gran número de trabajos que se distribuyeron en copias de off-set. Añádase el descubrimiento de Witold Kula, interviniente en Leningrado y cuyo famoso libro sobre el modelo señorial polaco se pudo adquirir allí mismo en edición francesa. El estudio de aquel amplio número de trabajos y el empeño de darlos a conocer en España (en varias crónicas publicadas en la Revista HISPANIA, 1971, vid. nota 8) nos dejaría un indudable peso formativo. 
El equivalente en España a lo que entonces significaba en Portugal el magisterio de los Fortunato de Almeida, Damiâo Peres, Paulo Merêa, Souza Soares o el francés Pierre David. Los códigos que se estudiaban eran los de la preceptiva alemana (las respectivas Introducciones al estudio de la Historia de Bernheim, 1914, o de Bauer, 1921; en sus traducciones al español publicadas en Barcelona en 1937 y 1952 respectivamente), que eran los prontuarios teóricos para las generaciones más jóvenes, es decir las nuestras.

Formados en la estricta normativa del positivismo científico (cf. también la Introduction de Langlois-Seignobos, 1898), aquellas generaciones de historiadores prestaban juramento de fidelidad al hecho objetivo, previa la debida verificación de la fuente. La operación histórica por excelencia consistía en la exacta determinación del hecho ("Juan sin Tierra pasó por aquí") previa una minuciosa crítica de la fuente (crítica externa o de autenticidad); a esta buena máxima se acomodaban aquellas generaciones de maestros. De esas preceptivas y maestros los alumnos aprendíamos a distinguir entre una opinión y un hecho; y que era necesario verificar las opiniones, incluso científicas, por su confrontación con los hechos tal como venían dados en las fuentes, contrastando varias de ellas siempre que era posible. Sana doctrina de la que depende la razón de ser de nuestra disciplina y que debe ser conservada en esa parte, ya que formaba historiadores convincentes, serios y creíbles, cualquiera que fuese el campo de aplicación de sus inquietudes. Faltaba solamente una toma de conciencia sobre la jerarquía de los hechos y su diferente relevancia, o más bien una apertura epistemológica para tratar de penetrar en las claves de los dos grandes ejes vectores del conocimiento histórico: la organización de las sociedades (jerarquía, función, propiedad, renta) y la formación de la cultura popular (inducción, experiencia, mito exotérico).

En ese ambiente se orientó la tesis doctoral del autor de estas reflexiones sobre un tema de historia política y del pensamiento político del siglo XIX, típico de la metodología alemana de la que estábamos impregnados, y que por entonces contaba en España con notables cultivadores. El interés por la historia de los partidos políticos decimonónicos duró lo suficiente para cumplir a satisfación sus efectos académicos. Pero al día siguiente de la lectura de aquella tesis doctoral (Universidad de Madrid, 1957), su autor se sintió ligero de conocimientos sobre todo lo demás. Aún ciñéndose estrictamente a ese siglo, tenía la sensación de que la realidad del siglo XIX español 
(el ferrocarril, el comercio, la fábrica, la producción y el hambre de trigo, el salario, la medicina, la higiene, la escuela pública, la tuberculosis, el cólera, las penúltimas crisis de subsistencias) se le había escapado sin sentirlo mientras se ocupaba en analizar las proclamas y manifiestos teóricos de unos y otros partidos políticos que se disputaban la audiencia. Esa sensación de vacío, y en cierto modo de hastío o de hartazgo por una sobrealimentación en historia política, abrió el apetito a la incorporación de otras influencias que empezaban a llegar a través de las publicaciones (francesas o no) por aquellos años de tránsito entre décadas. Entre las que no caían en saco roto las chanzas de Bloch y Febvre a costa de "robespierristas y anti-robespierristas" o contra los historiadores "jueces suplentes del valle de Josafat".

El descubrimiento de nuevas corrientes historiográficas que se ocupaban de otras realidades vitales (en el pasado como en el presente) se haría sólo en la siguiente década, cuando se pudo beber en las fuentes directas de los autores franceses; comenzando por la lectura de Lucien Febvre y de Marc Bloch; y no sólo de estos adelantados de entreguerras sino también de otros diversos autores de postguerra que encontrábamos recensionados en la Revista Española de Historia, algunas de cuyas obras se pudieron adquirir.

\section{El influjo directo. Las revistas francesas y el movimiento editorial de los años 60}

En los albores de los años 1950, cuando el autor de estas páginas obtenía su licenciatura en Historia, varios jóvenes historiadores peninsulares trabajaban ya en Paris con Fernand Braudel en su gran encuesta sobre el comercio europeo del siglo XVI, entre ellos Vitorino Magalhães Godinho y José Gentil da Silva, sobre los que habrá que volver. Estaban también los españoles Felipe Ruiz Martín, Valentín Vázquez de Prada y Alvaro Castillo, que por esos años trabajaban al lado de Braudel en su programa de estudio de los mecanismos y redes de relaciones del comercio europeo a través de los registros del archivo de Simón Ruiz en Medina del Campo y de las cartas de mercaderes que contiene: los Rocaz, los Le Lou, los Bonvisi, los Frías de Ceballos, los de la Presa, los Cuéllar, los Curiel, los Maluenda, los Quintanadueñas. 
El movimiento editorial de la España de los cincuenta no era muy abundante ni fáciles las adquisiciones de libros extranjeros, aunque algo comenzaba a llegar a los anaqueles de las Facultades a través de la madrileña librería Sánchez Cuesta, y luego de la librería alemana Buchholz. Pero desde finales de esa década o comienzos de los años sesenta las prensas parisinas de la editorial que dirigía Braudel publicaban con regularidad los volúmenes de estudios programados sobre el comercio europeo y los orígenes de la Banca, u otros temas de importancia sobre la vida económica de la Europa renacentista y barroca. A través de las librerías madrileñas se recibieron los volúmenes publicados sobre las cartas mercantiles de Amberes, del vallisoletano Valentín Vázquez de Prada (SEVPEN, 1960) y sobre las relaciones mercantiles entre Florencia y Medina del Campo, del también vallisoletano Felipe Ruiz Martín (SEVPEN, 1965).

Las obras de los españoles habían sido precedidas por las del portugués José Gentil da Silva, quien años antes había publicado (SEVPEN, 1956 y 1959) sus cartas de mercaderes de Lisboa (los Gomes de Elvas o los Rodrigues de Evora e Veiga); y antes todavía por las de Vitorino Magalhães Godinho (SEVPEN, 1955 y 1969) sobre la economia del imperio portugués, la moneda y los precios en Portugal. Conocíamos por otra parte algunos trabajos de Virginia Rau, sobre el comercio de la sal de Setúbal, incluidas poco después sus aportaciones a las conferencias internacionales de historia económica de Estocolmo (1960) y de Munich (1965). ${ }^{4}$

4 Desde 1947 Vitorino Magalhães Godinho figuraba adscrito al centro parisino del CNRS, en 1950 aparecían ya sus primeras páginas en Annales, auspiciadas por Lucien Febvre y luego por Braudel, y en 1958 había defendido su tesis doctoral en la Sorbona sobre el oro y las especias en la economía del imperio portugués, precedida de una recopilación sobre precios y monedas en Portugal publicada también en la editorial de l'Ecole (1955). Indudablemente en la órbita de Fernand Braudel y del centro parisino, también Virginia Rau - a la que conocí personalmente en la que se celebró en Leningrado (1970) -, había hecho por aquellos años su aparición en las conferencias internacionales de historia económica de Stokolmo (1960) y de Munich (1965). José Gentil da Silva - compañero de mesa en la misma conferencia de Leningrado, donde compartíamos hotel -, era ya por entonces profesor ordinario de la Universidad de Niza; doctor también por la Sorbona, bajo dirección igualmente de Braudel (SEVPEN, 1959, 2 vols.), colaboraba en los Annales desde 1957 al menos. En las prensas braudelianas José Gentil da Silva había publicado sus cartas de mercaderes de Lisboa, los Gomes de Elvas, los Rodrigues de Evora y Veiga, así como sus análisis sobre la estrategia de los negocios lisboetas en los mercados de Burgos, Medina del Campo y Sevilla (1956). Como se echa de ver, era inconmensurable la ventaja que nos llevaba el grupo lisboeta en 
En la misma editorial braudeliana se publicaron por aquellos años otros libros de interés, entre ellos el de José Augusto França (SEVPEN, 1965) sobre la Lisboa de Pombal; los dos volúmenes del de Albert Silbert (SEVPEN, 1966) sobre las estructuras agrarias del Portugal "mediterráneo" alentejano; el de Pierre Chaunu (SEVPEN, 1960) sobre las Filipìnas y el Pacífico portugués; o el del peruano Guillermo Lohman Villena (SEVPEN, 1968) sobre el negocio de la familia Espinosa entre Sevilla e Indias, entre otros.

Aunque con algún retraso, en esos años llegaron también las tres grandes tesis francesas que trataban sobre España, a saber, la Méditérrannée de Braudel, que llevaba varios años traducida al castellano (México: FCE, 1953), la Catalogne de Pierre Vilar (Paris, 1962), de gran impacto, y la monumental obra de los esposos Chaunu sobre Sevilla y el Atlántico (Paris, 1955-59). Junto a otro puñado de obras importantes de la escuela francesa, entre ellas la traducción española del Erasmo y España de Marcel Bataillon (FCE, 1950, $2^{a}$ ed. 1966); el libro de Marcelin Defourneaux sobre Pablo de Olavide (PUF, 1959) y los de Henri Lapeyre sobre Simon Ruiz de Medina del Campo y sobre la familia de mercaderes de los Ruiz (A. Colin, 1955). Uno de los más seductores sería el Erasmo de Bataillon, que junto con los de Defourneaux, Demerson, Lucienne Domerge, François López, etc. y más tarde Michel Vovelle, abriría el interés por una nueva apertura a otros estudios sobre cultura y mentalidades populares, en las nuevas cohortes de doctorandos que más tarde se irían incorporando. ${ }^{5}$

el dominio de las nuevas metodologías, aunque limitadas al sector de la historia mercantil, apanage privativo de Braudel y los braudelianos.

5 Entre las primeras adquisiciones, y para empezar, las obras de Bloch y Febvre. BLOCH, Marc-Apologie pour l'histoire ou Métier d'historien. Paris: Armand Colin, 1952, $2^{\mathrm{a}}$ ed. fr. (México: FCE, 1957, $2^{\mathrm{a}}$ ed. en español). Del mismo: Les caractères originaux de l'histoire rurale française. Nouv. Ed. Supplém. par R. Dauvergne. Armand Colin, 1968, 2 vols.; FEBVRE, Lucien - Combats pour l'histoire. Paris: A. Colin, 1953 (Trad. esp. Barcelona: Ariel, 1970). Del mismo: Pour une histoire à part entière. Paris: SEVPEN, 1962. Las obras de Bloch las adquirí también para mi uso personal. Las de Pierre Goubert acabé por tenerlas todas en mi personal cuarto de libros, por gentileza especial del autor. Con el primer número de 1966 iniciamos la adquisición regular de la revista Annales, así como de la Revue Historique, de la Revue d'Histoire Économique et Sociale que dirigía Labrousse y de los Annales de Démographie Historique que dirigía Goubert. Todos ellos pilares necesarios para asentar la iniciativa de 1973. 
El movimiento editorial parisino, del que no es posible hacer aquí un repaso exhaustivo, se intensificó en los años sesenta hasta rozar la avalancha. Lo mismo en P.U.F. y en las editoriales privadas (Armand Colin, Mouton, Fayard, Flammarion, Privat de Toulouse, Droz de Genève). Afortunadamente los recursos económicos de nuestra cátedra aumentaron también a partir de 1965 (ó de 1966, con la creación del Departamento de Historia Moderna), lo suficiente para adquirir todas esas novedades editoriales entre otras, además de cubrir diversos huecos que se echaban en falta, incluyendo la suscripción a las principales Revistas de bandera. ${ }^{6}$

\section{De Leningrado a Compostela. Las Jornadas de 1973, antecedentes y continuidad}

Las influencias del exterior iniciadas con las adquisiciones directas de libros y revistas de Francia se ampliaron considerablemente el año 1970, por el influjo de otras aportaciones de historiadores de diversos países a los congresos internacionales celebrados ese año en Leningrado y Moscú. En el Tupolev que nos condujo de París a Leningrado para asistir al quinto congreso internacional de historia económica, un día de agosto de ese año, viajaba también un nutrido grupo de historiadores franceses de primera línea, cuyas publicaciones nos eran familiares de años atrás y a los que sólo entonces pudimos poner rostro humano. La asistencia a esos dos congresos brindaba con ello una oportunidad de iniciar el acercamiento directo a los centros de la historiografía que más interesaba.

Durante aquella estancia en la capital del Neva, y luego en el congreso internacional de ciencias históricas de Moscú que se solapó inmediatamente, surgirían algunos contactos personales útiles para orientarnos en la dirección

6 Las menciones aquí hechas a algunas de las adquisiciones por entonces realizadas de libros extranjeros, entre ellos el de Albert Silbert, nos hacen pensar que eso era lo normal igualmente en las Universidades portuguesas por las mismas fechas. Los dos gruesos volúmenes de la obra de Silbert, junto a las de José Augusto França, José Gentil da Silva, Magalhães Godinho y quizá alguno más, se hallaban bien visibles sobre la mesa de trabajo del Prof. Luis Ferrand de Almeida cuando nos recibió por primera vez en Coimbra, en compañía del Prof. Salvador Dias Arnaut, en diciembre de 1968; una bella estampa que guardo en mi retina de un conjunto ordenado de libros que nos resultaba muy familiar por aquellos años. 
de lo que se buscaba; entre ellos Pierre Jeannin, notable especialista del comercio con los países del Norte (PUF, 1969), por aquellos años secretario del Centre de Recherches Historiques; Marcel Couturier (tesis SEVPEN, 1969), que se ocupaba de la programación informática - un novísimo instrumento de trabajo en el que tratábamos de iniciarnos por entonces en el citado Centro; y José Gentil da Silva (tesis SEVPEN, 1959), entonces profesor en Niza y que había trabajado años atrás en el mismo Centro parisino dirigido por Braudel. Si de aquel viaje de agosto de 1970 pudo haber nacido la idea inconcreta de hacer algo más, la oportunidad de concretarlo y hacerlo realidad nos vendría dada un par de años más tarde con la ocasión o el pretexto del cincuentenario ya recordado.

En el programa del segundo de aquellos congresos, el de Moscú, destacaban dos grandes temas; de ellos la sección B), dedicada al enfoque individual de la historia ("El papel de la biografía en las ciencias históricas"), parecía interesar más a los historiadores alemanes e ingleses, todavía fieles al paradigma alemán los unos o apasionados de la escuela de Carlyle los otros. Personalmente íbamos más motivados por la sección A), dedicada monográficamente a las posibilidades de empleo de la historia cuantitativa ("El número como elemento de información del historiador"). Dentro de ésta, lo de mayor tirón parecían ser las sesiones dedicadas al computador ("La machine et la recherche historique"), organizadas por el comité francés y cuya exposición corría a cargo del grupo de l'École. Por entonces ya conocíamos el libro de Couturier y algún otro trabajo realizado con ayuda del computador; eso era lo que interesaba para sustituir a la calculadora eléctrica de rodillo con la que se venía trabajando. Tardaríamos sin embargo algunos años más en dar el salto al ordenador personal y a la hoja lotus, limitándonos por algún tiempo a hacer uso de los servicios informáticos del centro de cálculo de nuestra Universidad. ${ }^{7}$

Más variada era la oferta que se brindaba en el congreso de Leningrado. Entre el innumerable tropel de los rusos, lo que allí atrajo nuestra atención fue el joven y animoso grupo de la historiométrica soviética (I. Kovalchenko,

7 Allí en Moscú escuchamos por primera vez de viva voz a Le Roy Ladurie, junto a Jacques Bertin y a Marcel Couturier, de los que ya se conocían algunos trabajos. En aquella experiencia se gestó probablemente la idea de nuestros primeros trabajos informatizados (sobre precios, padrones de vecinos, etc.) que se presentarían a las Jornadas de 1973. 
H. Palli, Yu Kahk), que venían aplicando con éxito la informática al estudio masivo de las fuentes letonas y lituanas sobre temas de historia rural (los precios de mercado de los cereales, el ganado, el peso de las rentas y de la corvea, todo influido a mi parecer por la vecina historiografía polaca). Pero el mayor descubrimiento de aquel viaje fue sin disputa el compacto grupo de los historiadores polacos (Witold Kula, Henry Samsonowicz, Jerzy Jedlicki, Jerzy Topolski, Andrzej Wyczanski, Maria Bogucka, Janina Leskiewicz, Anthony Maczak), con su aprovechamiento sistemático de las instructa o contabilidades privadas del gran dominio de la Europa oriental aplicadas al estudio de las economías señoriales y de las relaciones sociales. Tanto la reflexión personal sobre el modelo señorial polaco, analizado estructuralmente en el magistral libro de Kula, como la autodisciplina de sintetizar y comentar todos los trabajos de diversa procedencia presentados en lenguas accesibles a un congreso especializado y de temática compleja como aquél, serían provechosos ejercicios de paciencia con efectos indudables para nuestra formación personal. ${ }^{8}$

\section{Las ideas directrices: Labrousse, Goubert, Le Roy Ladurie y otros guías}

Hasta aquí nos hemos detenido en hacer repaso del movimiento editorial de los años sesenta y anteriores con gran número de publicaciones de múltiples autores y sobre temáticas muy diversas, aunque todas ellas con un mismo impulso innovador, que sirvieron para preparar el ambiente - y para prepararnos instrumental e intelectualmente - con miras a la funcionalidad del encuentro científico de 1973 y de su complementario que tendría lugar en 1982. Pero en el medio social y económico en que se trabajaba en Galicia, de base tradicional campesina y agropecuaria, y en el mundo de los archivos locales disponibles en el norte y oeste peninsular, generados por una sociedad

8 "Un modelo típico de las economías de base agraria" [Recensión del libro de W. Kula (1970) en HISPANIA. 119 (1971) 659-671]. En números precedentes de la misma Revista y año publicamos las dos crónicas sobre los numerosos trabajos de aquel enriquecedor congreso: "El V Congreso Internacional de Historia Económica de Leningrado. Resumen temático" en HISPANIA. 116 (1970) 701-718 y 117 (1970) 215-239. 
preindustrial escasamente mercantilizada y mediocremente urbanizada, los más orientadores resultaban ser otros libros de dimensiones mayores, de enfoque más complejo y de temáticas más diversificadas. A saber, algunas de las primeras grandes tesis francesas que hacían realidad el ideal globalizante de la "historia total" (à part entière) de Febvre, sobre un conjunto social histórico determinado, con ambiciones de totalidad: desde las estructuras de la propiedad a las coyunturas de la producción y de la renta, también las del consumo; desde las vicisitudes de la población hasta el encuadre profesional y económico de los grupos sociales; desde las condiciones materiales de vida hasta las normas de conducta colectivas, las prácticas colectivistas, la religiosidad y las mentalidades populares. De entre los autores de algunas de esas grandes tesis serían extraídos los cabezas de serie encargados de marcar algunas ideas directrices renovadoras para las sesiones de trabajo de los encuentros científicos de 1973 y $1982 .{ }^{9}$

9 Para las Jornadas de Metodología de 1973 fueron solicitados como cabezas de cartel de las diferentes secciones los historiadores franceses en ese momento más requeridos. Por una excepcional fortuna pudimos obtener del autor de la Esquisse, ya octogenario entonces y considerado maestro de todos los demás en la Sorbona, la presentación del rapport introductorio a la sección dedicada a precios, salarios y fluctuaciones de coyuntura. Cf. LABROUSSE, E. - Aspects d'un bilan méthodologique et critique de l'histoire conjoncturelle, in Actas 1973, III, p. 587-595. Por ser entonces director de la SFDH y de los Annales de Démographie Historique, por ser el autor del primer método de reconstrucción de familias entonces usado y por la importancia singular concedida en su tesis, más que en ninguna otra, al estudio de la población en sus aspectos metodológicos precisos, se encomendó al autor del Beauvaisis el rapport introductorio de la sección consagrada a esta materia, cf. GOUBERT, P. - Histoire démographique in Actas 1973, III, p. 253-273. En su lugar se echó mano del autor del Languedoc para confiarle el rapport introductorio de la sección de historia rural, quien cumplió con su brillantez acostumbrada defendiendo una novedosa monografía sobre un sector particular de tan extenso campo, cf. LE ROY LADURIE, E. - Un cas de méthodologie dans l'histoire rurale: Les grandes monographies des révoltes et des contestations rurales en France de 1675 à 1788 in Actas 1973, III, p. 33-51. La cuarta sección de las Jornadas de Metodología, dedicada a los temas específicamente braudelianos del comercio, el crédito y la banca, era obligado confiarla a uno de los competentes discípulos españoles de Braudel, autor de sólidas monografías sobre la Banca genovesa en España y sobre las relaciones mercantiles con Génova y Florencia, cf. RUIZ MARTÍN, Felipe - Crédito y banca, comercio y transportes en la etapa del capitalismo mercantil in Actas 1973, III, p. 723-751. 


\section{1/ Ernest Labrousse}

a/ Labrousse: técnicas estadísticas; los precios.

b/ Labrousse: la renta dominical y feudal.

c/ Labrousse: el salario, la crisis de subconsumo industrial y el paro.

d/Labrousse: el interciclo (1778-1787) y sus efectos sobre la agricultura.

el Labrousse: la estructura económica preindustrial.

En el origen de las grandes tesis francesas que debían servir de modelo estaban por supuesto las de Labrousse y Braudel; sobre ésta última y su resonancia en España no era ni es necesario insistir. Más adaptada a nuestras ncesidades desde el punto de vista metodológico y temático, por ser el padre de la historia cuantitativa y el introductor de las técnicas estadísticas aplicadas a la historia (en la estela de su maestro Simiand, pero de un modo mucho más concreto y adaptado a las necesidades del historiador común), nos parecía la obra de Labrousse, una tesis de Estado sobre el movimiento de los precios, el salario y la renta en la Francia del XVIII que se remontaba a 1933. En ella el autor se elevaba del "movimiento de los precios y de los ingresos" (reunidos en las series numéricas de los estados de las "generalidades" de Francia), a la situación de los hombres, fin último del historiador. ${ }^{10}$

En la huella de los teóricos Paul Lacombe y François Simiand, pero como más sentido histórico y humano, Ernest Labrousse aparecía como el hombre-puente entre la primera y la segunda generación de Annales, y como un explorador (desde el primer tercio del siglo XX ya) de los caminos que era necesario abrir para la aproximación entre la historia social y las llamadas

10 "Deberá considerársela - dice el autor en el proemio sobre su obra - como una introducción a la historia de la condición de las personas en el siglo XVIII". La Esquisse de Labrousse (Paris: Dalloz, 1933), no figuraba entre los fondos de biblioteca que teníamos a nuestro alcance por aquellos años y no llegamos a tiempo de adquirirla, hasta su segunda edición ya muy tardía. Pero existía una traducción abreviada al español sobre las fluctuaciones económicas en relación con la historia social de la Francia del XVIII (Madrid: Tecnos, 1962), que conservo entre mis libros de cabecera y que cumplía para nuestro propósito de conocer el pensamiento y técnicas de aproximación del autor, debidamente complementada por las aportaciones del mismo a diferentes congresos y por la magna historia económica y social de Francia que Labrousse dirigió conjuntamente con Braudel y que alimentó durante años nuestras explicaciones de clase (Histoire Économique et sociale de la France, 1660-1789. Paris: P.U.F., 1970-1976). 
ciencias sociales (economía, sociología, demografía), siendo el análisis de las sociedades el fin y el método estadístico (simplificado y accesible) el medio que se ofrecía al historiador. Con el recurso de la abundante documentación que guardaban los archivos fiscales de Francia (o de cualquier Estado moderno), Labrousse se esforzaba en superar el nivel de los relatos de corte narrativo o descriptivo sobre la sociedad de Ancien Régime con su propuesta de un método de clasificación socioprofesional basado en la propiedad y la riqueza como fuente de ingresos de los grupos profesionales (en su famosa propuesta al X Congreso de Roma, en 1955) con base en la documentación de padrones y archivos fiscales como fuente específica para esa encuesta. Su no menos famosa polémica con Roland Mousnier, que a su vez proponía su propia clasificación socioprofesional basada en el prestigio social y en la función de los individuos y de los linajes, se nos aparecía como más bien artificiosa o necesitada de un nuevo enfoque empírico y superador, capaz de reducir la oposición de dos criterios tal vez más complementarios que antagónicos. Del marxista ecléctico y objetivo Labrousse tomamos entonces algunos criterios de objetividad a seguir. Frente a la impresión subjetiva y no verificada, la tesis de Labrousse ofrecía la relativa seguridad de criterios como el del test de concordancia fundado sobre un amplio número de casos y el de la comprobación estadística.

\section{Labrousse: técnicas estadísticas; los precios.}

De la tesis de Labrousse podíamos aprender no sólo las posibilidades de algunas sencillas técnicas estadísticas al servicio de la historia social (el análisis de variación de conjuntos, el coeficiente de correlación), sino sobre todo la lectura a través de los más sencillos indicadores estadísticos del bienestar o la miseria de las poblaciones estudiadas, de la abundancia o la escasez de las cosechas, de sus efectos diferenciales contrapuestos para los diferentes grupos sociales, según su posición en relación con la propiedad, la producción y el mercado. Con pura lógica científica y con sondeos bien dirigidos sobre la documentación administrativa de los archivos de las generalidades y de la Oficina de Subsistencias dependientes del Control Général de Francia, la gran tesis de Labrousse (1933) analizaba para la Francia del XVIII los efectos del movimiento estacional y del movimiento cíclico (de los cereales principalmente) para los diferentes grupos sociales 
de productores y de consumidores, de vendedores o de compradores, de pequeños productores en economía de subsistencia o de productores excedentarios en economía de mercado.

Tanto en la larga duración secular como en el movimiento corto de los ciclos agrícolas (algunos más benévolos en la fase larga del XVIII, otros más terribles en los comienzos de ese siglo y finales del anterior), el juego combinado de la producción y de los precios mostraba efectos contrapuestos sobre el mediano cultivador-vendedor, sobre el pequeño cultivador-comprador y sobre las masas de consumidores urbanos depauperados en años de "mínimo cíclico" y de "máximo cíclico" respectivamente (todo ello en la terminología labroussiana, que sería conveniente recuperar para el estudio de las economías de subsistencia); lo que en definitiva aportaba un análisis del movimiento de los precios más propiamente histórico y con más sentido de las repercusiones sociales que el estrecho método economicista o monetarista del norteamericano Hamilton en el que con anterioridad nos situábamos. ${ }^{11}$

El estudio de Labrousse, centrado en el análisis de las fluctuaciones de los precios de los cereales, no se detenía en ellos. Abarcaba a todos los principales artículos de consumo popular y sus precios. El tocino, las legumbres, la leña, las velas de sebo, y sobre todo el pan de tahona: la media familiar de 8,21 libras de pan al día según Dupont de Nemours, o entre el mínimo de 6,39 y el máximo de 9,86 libras diarias según las investigaciones directas; media más próxima a la primera cifra que a la segunda (4 hectólitros de trigo por persona y año). A partir de ellos Labrousse analiza el movimiento del coste de la vida popular y del salario expresado en bienes de consumo: las variaciones

${ }^{11}$ Cf. LABROUSSE, E. - Fluctuaciones económicas e Historia Social. Madrid: Tecnos, 1962, 478 p. Versión comercial de la tesis de Labrousse de la que bebimos directamente una nueva metodología para el tratamiento de la producción y de la renta, de la evolución de los precios y de los salarios y sus consecuencias sociales, que inspiró varios de nuestros trabajos, entre ellos el de la progresiva degradación del salario real en Galicia (Coloquio de Bendor, Niza 1974) más abajo citado. A esa línea metodológica rendimos homenaje en una comunicación presentada a las Jornadas de 1973, haciendo con las técnicas estadísticas del propio Labrousse, que presidía la sesión, una reelaboración de sus series de precios franceses (agrícolas) publicadas años antes por Labrousse-Romano-Dreyfus (SEVPEN, 1970; recensión en HISPANIA, 120 (1972)). Para éste último trabajo, vid. Actas 1973, p. 623-650. 
de un modo de vida en la cual la casi totalidad de los gastos corresponden a alimentación, vestido, lumbre, calefacción y alumbrado (con una ínfima estimación para los costes del vestido). "En cuanto al calzado, el trabajador del campo usa sobre todo zuecos de madera y en algunas regiones va con los pies descalzos. Young encuentra campesinos que vienen de la ciudad con los pies desnudos y sus zapatos en el cesto" (Fluct. Econ..., p. 292-298).

\section{Labrousse: la renta dominical y feudal.}

Para el estudio de la renta y la renta feudal (diezmo, etc.), Labrousse fue tal vez el primero en echar mano de la "notable riqueza" de los archivos eclesiásticos y hospitalarios, de los cabildos, de los monasterios y de colectividades. En su trabajo sienta las bases del método serial: sobre decenas y decenas de series largas de contratos de arrendamiento formadas a partir de 74 dominios distribuidos en cinco generalidades de Francia, fue el primero en constatar esa perspectiva trágica para el campesinado dependiente en trend de crecimiento demográfico: el efecto perverso de la coyuntura alcista que juega en favor del arrendador contra el arrendatario, incluso si se trata de campesino productor para el mercado. Aplicando el test de concordancia a sus series regionales de la renta verifica la constancia de "un movimiento análogo violentamente ascendente (de la renta) muy superior al de los precios agrícolas" (Fluct. Econ..., p. 181-184).

Para el pagador de la renta, igual efecto adverso de las fluctuaciones del movimiento cíclico de la producción y de los precios, siempre favorables al gran propietario perceptor de rentas en especie, al gros décimateur y al beneficiario de la renta feudal (diezmo y "champart", proporcionales a la cosecha). Para los fisiócratas (Quesnay, Dupont de Nemours, Turgot) el movimiento de la producción entre año malo y año bueno variaba de tres a siete setiers por arpenta. Una vez consideradas las detracciones de la simiente y el diezmo, L. establece sus propias proporciones: la relación 10/21 entre año malo y año bueno para la producción (coef. 0,47), la relación 25/9 para el precio del cereal (coef. 2,77), ergo relación 7,5/5,6 a favor de los ingresos del perceptor de la renta feudal (coef. 1,33). Los años malos lo eran para el pagador tributario de rentas en especie, y buenos para su perceptor. Repárese que estas constataciones preciosas estaban adelantadas desde 1933 y que también al lector peninsular le fueron accesibles en traducciones años antes 
de las grandes tesis ruralistas que llegarían sólo después de la guerra, más bien después de $1960 .^{12}$

De Chajanov a Labrousse: el salario y la autoexplotación del trabajador.

A su vez la tesis de Labrousse asentaba el método de análisis - todavía no superado, creemos - de la evolución y fluctuaciones de los salarios de los trabajadores de campo y ciudad: verificadas para la Francia del XVIII a partir de 72 series largas (61 series locales y 11 regionales o de "generalidad") de salarios de trabajadores del campo y de la construcción, extraídas de las contabilidades de hospitales, colegios, cabildos, municipios y conventos, o de hortelanos, viñadores y jornaleros de los libros de algunas abadías; a lo que suma los informes de la documentación reunida por la Inspección de Manufacturas y las encuestas sobre presupuestos familiares realizadas por los fisiócratas (Messance, Dupont de Nemours, más tarde Villermé y Le Play). Con ello aportaba la primera comprobación histórica de los efectos negativos del trend alcista del crecimiento demográfico (el del XVIII) sobre el salario de los trabajadores: el precio de la mano de obra sube en el transcurso del siglo menos que el de los productos agrícolas, y el de éstos menos que el alza de los arrendamientos.

La estabilidad nominal del precio del trabajo era un hecho reconocido por los fisiócratas, frente a la enorme movilidad de los precios del trigo y al alza de la renta. Las 61 series de Labrousse (concordancia) muestran que el alza de larga duración del salario es considerablemente inferior a la de los precios y la renta, al menos hasta 1789; luego el salario del trabajador y el coste de la vida tienden a compensarse por algún tiempo, entre 1789? y 1812, para volver a degradarse la situación en el siglo siguiente. Entre el período

12 "Los años de gran carestía, los años de escasez, representan años de abundancia para el beneficiario de arrendamientos pagados en especie. El alza de sus ingresos sobrepasa considerablemente la de los precios de los productos agrícolas. Los años de escasez son los mejores para los perceptores de diezmos y de derechos feudales. El alza de los precios compensa con creces la baja de la productividad y se traduce en un aumento de la renta" (Fluct. Econ..., p. 189-192). No se olvide que estas conclusiones tienen validez para países o regiones en los que se mantiene el sistema de percepción de la renta en especie. Lo que tiene validez universal para el estudioso de la historia social es el tino de ascender de los datos a los hombres. "Estudiar las situaciones y fluctuaciones económicas significa para el historiador perseguir las variaciones en los ingresos y en el bienestar de los hombres". 
base de 1726-41 y los años extremos de 1785-89 el alza nominal del salario pagado en dinero fue de 22 por ciento (media general); el alza del coste de la vida fue del 62 por ciento, según el índice medio del coste de la vida popular calculado por Labrousse. Reacción: aumenta la parte dedicada al pan en el presupuesto del trabajador, mientras desaparecen progresivamente otros consumos como la carne. El pan solo llega a exigir el 88 por ciento del salario (Fluct. Econ..., p. 247-253 y 305-307). ${ }^{13}$

A su vez en el movimiento cíclico, lejos de acompasarse al alza de los productos agrícolas, el salario valorado en dinero o en bienes de consumo sigue un movimiento inverso: así en 1772 por ejemplo, año de máximo cíclico de los precios del trigo y de todos los cereales panificables, se registra en la generalidad de Amiens una baja del salario nominal cotidiano. En la misma generalidad y año el subdelegado de Amiens escribe al intendente que la miseria y el paro obliga a los obreros "a disminuir el precio de sus jornales a medida que los granos subían". De este modo "el movimiento cíclico del salario nominal por jornada o a destajo se presenta en sentido inverso al de los precios agrícolas que intervienen en el coste de la vida del trabajador". En los años de carestía el salario por tiempo de consumo y el salario real se hunden para los trabajadores de la ciudad y el campo, por el doble efecto combinado de la contracción de la demanda y la inflación de la oferta de mano de obra desocupada. En todos los frentes se confirma la misma tendencia al "divorcio cíclico del precio de la mano de obra y del precio de los granos". Para hacer frente al descenso del poder adquisitivo del salario, el trabajador tiende a prolongar su jornada de trabajo; ésta tiene un límite natural en los horarios de la luz solar, pero fuera de eso "parece casi seguro que no disminuyó" (Fluct. Econ..., p. 259-265).

${ }^{13}$ La degradación del salario de los trabajadores urbanos en esa centuria ha sido confirmada luego en España, por Hamilton para Madrid y por Vilar para Barcelona, usando ambos la confrontación del salario nominal con los precios del trigo. Mediante un método inspirado de cerca en el de Labrousse (el salario expresado en unidades de consumo popular), por nuestra parte hemos verificado la "Degradación del salario real de los trabajadores urbanos en Santiago de Compostela" (lenta y gradual degradación secular 1730-1865, a partir del optimum de 1711-1727) en nuestra comunicación al coloquio de Bendor (1974) de la Universidad de Niza. (Cf. La force de travail dans les cités méditerranéennes. Cahiers de la Méditerrannée. S.S. nº 3 (1974) 17-56). 
La acción conjugada del movimiento cíclico y del movimiento de larga duración expresada en la relación entre producción y precios actúa consiguientemente en perjuicio de los sectores más modestos del campesinado, el pequeño propietario comprador (no autosuficiente en año malo), el arrendatario, el aparcero. El mecanismo contribuye a explicar los procesos de pauperización y de expropiación parcelaria del pequeño campesinado dependiente - "la masa de los propietarios compradores, cuyo patrimonio se desmigaja a cada reparto sucesorio" - condenado más y más a vender su propio trabajo como asalariado primero, a desprenderse de una parte de su propiedad luego, a completar el círculo de su proletarización finalmente como asalariado urbano, él o sus hijos, "puesto que nada tiene que vender excepto cantidades constantes de trabajo". ¿No se intuye aquí la influencia próxima del concepto de "autoexplotación" de A. Chajanov (1925) como aplicación creciente de trabajo humano para suplir la falta de rentabilidad de la pequeña unidad económica campesina, extensible aquí al trabajador tanto de la ciudad como del campo? (Fluct. Econ..., p. 227-229).

Labrousse: la crisis de subconsumo industrial y el paro.

Sin ocuparse apenas de aspectos descriptivos como los de la mendicidad, la asistencia pública etc., L. ofrece un medio de aproximación a las causas de la pobreza al estudiar los efectos sobre el empleo de la crisis de subconsumo industrial, generadora de paro y causa periódica de mendicidad, que cada poco se produce en los años recesivos de crisis cíclica.

Labrousse contrasta los movimientos de los precios agrícolas con los de la producción textil (tomados éstos de los estados de la Inspección de Manufacturas), para comprobar la discordancia cíclica u oposición de movimientos entre los precios de los cereales y la producción de paños y telas, en diferentes generalidades de Francia simultáneamente. La observación se extiende a la producción de varias regiones: paños normandos de Elbeuf (Rouen) y paños picardos de Amiens (lanas); telas normandas de Rouen o de Caen y lencería rural bretona (las delicadas bretañas). Antagonismo cíclico entre el movimiento de la producción textil y el precio de los cereales en años de máximo cíclico (malas cosechas): mientras éstos se duplican, la producción textil puede bajar un 25 por ciento o más. En el máximo cíclico de 1751-1752 la producción de paños llega a bajar un 50 por ciento 
en Rouen, conduciendo al paro temporal a los obreros del textil en el mismo año en el que el pan escasea y se encarece, duro panorama.

Hay que explicar luego por qué no existe a pesar de todo una correspondencia automática o mecánica entre las alzas de los precios locales del grano y las caídas experimentadas en la producción. La observación es compleja pues se entiende que los precios que influyen en la salida de las manufacturas son más los de los lugares de consumo (otras regiones de Francia, pero también fuera de ella) que los de los propios lugares de la producción en Francia, aunque los efectos sociales del paro industrial se perciban en éstos. El mercado exterior (España y Portugal en primer lugar, con sus respectivas colonias, consumidoras de los paños de Picardía o de las telas exportadas por la lencería bretona, etc.) es el principal mercado para los paños fabricados en el territorio de la Inspección de Amiens, entre otros, y análogamente para las telas bretonas y normandas.

Verificación de hecho como método de observación repetida: concordancia en diferentes puntos de observación documental entre el máximo cíclico de los precios de los cereales y el paro en la industria textil, durante la crisis prerrevolucionaria de 1789 por ejemplo. Valor explicativo: repercusión de las variaciones en los precios del trigo en el consumo de productos textiles como consecuencia del aumento del gasto en pan en el presupuesto del consumidor.

De ese modo la coyuntura general europea y americana repercute en la Francia textil. En 1775, año malo en Francia, los embarques de telas para Méjico reaniman el trabajo en los telares bretones. De 1778 a 1780 es la guerra de la Independencia americana la que explica la depresión de la actividad textil en Francia. En 1786-1789 son las consecuencias nefastas del tratado Eden de libre comercio entre Inglaterra y Francia las que provocan la invasión de las manufacturas inglesas y los motines de tejedores en paro que preceden a la Revolución en Francia.

Si se excluye ese tipo de azares dependientes de la gran política internacional, el resto del siglo es la crisis cíclica de la producción agrícola la que alcanza negativamente al conjunto de los ingresos agrícolas, industriales y comerciales y a todas las categorías de productores y de consumidores, "actuando en tres tiempos: baja producción agrícola, bajo consumo general popular, bajo consumo de productos textiles". En tiempos de pan caro, 
el asalariado aplaza cuanto le es posible los gastos en vestido. El alza local de los precios del trigo es también un factor en la recesión industrial de 1789: el trabajador que en 1789 paga el pan un 60 por ciento más caro que en 1786 sufre al mismo tiempo una grave crisis de trabajo; en Amiens la producción disminuye de 89.000 a 65.000 piezas entre esas dos fechas. De este modo se genera la crisis de subconsumo industrial creadora de paro y se materializa la "concordancia entre el pan caro y el paro" (Fluct. Econ ..., p. 276-291).

El Paro crónico. A los efectos imprevisibles del paro cíclico habría que sumar todavía los previstos del paro estacional (media de 200 días de salario al año para el artesano o el jornalero según la estimación de los fisiócratas; máximo de 270 días de salario para los trabajadores urbanos mejor establecidos) y de larga duración. Nada permite suponer que haya existido en el transcurso del siglo una disminución del paro "secular" o de larga duración, ya que la oferta de mano de obra crece más aprisa que la demanda en la agricultura o en la industria. Con las cifras del Comité de Mendicidad de la Constituyente (1790), Labrousse establece que el paro crónico en la agricultura y en la industria (de cuatro a cinco millones de hombres) equivale al crecimiento de la población francesa en los treinta años anteriores. "La desproporción entre la población de Francia y el trabajo que le proporciona - decía el Comité - es la causa primera y principal de la indigencia" (Fluct. Econ..., p. 255-259).

Unos mecanismos explicativos que en principio se suponen de validez general dentro y fuera de Francia - a confirmar por los resultados de la investigación empírica en cada tiempo y lugar - sobre las alteraciones que producen en las condiciones de vida de las masas de trabajadores de campo y ciudad las fluctuaciones cíclicas de la naturaleza y de la agricultura (de "mínimo cíclico" a "máximo cíclico"), las variaciones estacionales con su impacto sobre las reservas de alimentos y la oferta o demanda estacional de trabajo, y todavía a mayores, el trend o tendencia secular de la demografía con su modificación lenta y a largo plazo de las condiciones de oferta de mano de obra y demanda de empleo. El estudio de las migraciones, no contemplado en la obra de Labrousse, debería engancharse aquí como un vagón más de este lento convoy, a continuación del estudio del crecimiento demográfico (cf. Jean-Pierre Possou, 1983). 
Labrousse: el interciclo (1778-1787) y sus efectos sobre la agricultura.

Además de la metodología labroussiana de la historia serial, de los precios, de los salarios y de la renta; de la técnica de deflactar el salario en equivalente-grano; de la idea estadísticamente verificada de la degradación progresiva del salario real a compás del crecimiento demográfico del XVIII, etc., otra de las constataciones puntuales de este autor sobre la coyuntura agraria del XVIII, que ha podido ser recuperada también para Galicia y regiones del norte peninsular, ha sido el famoso interciclo de buenas cosechas y de precios bajos señalado por L. para la agricultura francesa a lo largo de la década de 1780, en vísperas de la Revolución (Labrousse, La crise de l'économie francaise..., 1944). Una fase de cosechas abundantes cuya precisa cronología (años 1778 a 1787 en Francia) y motivaciones climáticas son hoy bien conocidas por los historiadores franceses del clima (cf. op cit. de Desaive, etc., Mouton 1972), al igual que sus efectos sociales contrapuestos según se trate del gran propietario vendedor y del viticultor de mercado, beneficiados por el alza de precios, o del pequeño cultivador-comprador y del consumidor urbano, beneficiados por las cosechas pletóricas. El alza de la producción durante los años de ese interciclo se detecta con claridad en Galicia en las series de diezmos de Mondoñedo de 1778 a 1791; en las series del obispado de Santiago en los mismos años y en las del obispado de Orense de 1777 a 1792. En la curva general de los diezmos gallegos la recuperación se inicia en 1778, el mismo año que en Francia, y sus efectos se prolongan hasta 1791, dos o tres años más que en Francia, para instalarse en la crisis ya desde 1792 (Eiras Roel, 1982, apud J. Goy, etc., Prestations, I, p. 354 passim). Al contrario que en Francia, por esos mismos años los efectos favorables apenas se acusan en los precios de los cereales de consumo popular en Galicia, lo que plantea el problema de su atribución a un incremento de la demanda y del consumo por el efecto poblacional, o más bien a factores perturbadores de carácter especulativo (posibles exportaciones de granos a regiones deficitarias de la España seca o del sur de Portugal); pero los efectos sí se acusan en el alza de las series diezmales de la producción (Eiras Roel 1982, ibid.), así como se registra la brusca subida de los precios gallegos en el ciclo agrario de 1791 a 1804 y en el siguiente, una vez desaparecidos los efectos saludables del interciclo (Actas 1973, III, tablas p. 677 passim). 
Interciclo y método comparado: Los efectos del interciclo en las cosechas y con más salvedades en los precios gallegos se detectan o se intuyen en las series numéricas de varios trabajos publicados entre 1973 y 1982 y ya mencionados; pero la presencia explícita del interciclo labroussiano como tal sólo aparece identificado por primera vez fuera de Francia en el trabajo relativo a Galicia presentado al coloquio madrileño de la Casa de Velázquez (Eiras Roel, 1984, p. 408 passim). Lo señalamos con alcance más general para todo el norte, centro y oeste peninsular en un trabajo sobre la evolución agraria en la España de los siglos XVII y XVIII que se presentó muy abreviado para el congreso de Stuttgart en 1985 (Ordina, 1987, p. 113-121), y que se recogió in extenso en un volumen publicado poco después (Estudios sobre agricultura y población..., 1990, p. 131-185). De este trabajo realizado a partir del trazador de las curvas diezmales se desprende que los efectos del interciclo, producidos por la entrada de masas de aire cálido de origen sahariano, se aprecian en las regiones de clima templado del centro y norte peninsular (con primaveras frías y lluviosas de ordinario, igual que la de 2013, y con frecuentes veranos "podridos"), en los diezmos de Galicia y de Asturias como en los de Segovia y Tierra de Campos, tierras cerealeras, como también en la Rioja vitícola. Las inversiones climáticas hacen que por el contrario en los diezmos de Valencia y Murcia, y en general en la España tórrida del Levante y sur, no se experimente beneficio alguno de ese interciclo de inviernos templados y veranos secos, como tampoco en la Baja Provenza o en Languedoc (Eiras Roel, 1990, ibid. p. 168-169).

Si en ausencia de curvas diezmales o de curvas parroquiales se presta atención a los precios de los cereales, los beneficios del interciclo parecen insinuarse asimismo en otras áreas de la geografía peninsular, como la fachada atlántica portuguesa: descenso largo de los precios del maíz en Oporto de 1773 a 1778; de forma menos intensa o menos ininterrumpida, también de los precios del trigo en Lisboa y en Évora, según las series de precios publicadas por Magalhães Godinho (SEVPEN, 1955), idem en los precios del Algarve (J. Romero de Magalhães, 1993). Esa intuición sobre el efecto diferencial de las inversiones climáticas, formada sólo a partir de la evolución de los precios y creemos que todavía no suficientemente estudiada a nivel peninsular, sugiere en todo caso que en el territorio portugués los beneficios del interciclo se perciben cada vez menos a medida que se avanza 
de norte a sur y de la costa hacia el interior: en Viseu menos que en Oporto, en Lisboa también menos que en Oporto, en Évora menos que en Lisboa o que en Viseu, en Beja supuestamente menos que en Évora, en Loulé en la costa del Algarve nada de beneficios de la climatología durante el interciclo. Tendría su lógica que en el Portugal "mediterráneo" de Silbert las masas de aire cálido de origen sahariano trajesen pocos beneficios, como tampoco se perciben (en 1787-1778) en la Baja Provenza de Baehrel ni en el Languedoc de Le Roy Ladurie.

\section{Labrousse: la estructura económica preindustrial.}

De los posteriores contactos de Labrousse con el estructuralismo extrajimos finalmente (post 1968) un concepto de estructura económica preindustrial adaptable a la realidad de la época en el norte y el oeste peninsular entre otras regiones, con el peso aplastante de la agricultura sobre la economía (más bien lo agropecuario en el caso peninsular), con una agricultura dominada a su vez por el problema de la variabilidad cícicla de las cosechas, sin medios de circulación baratos para distribuir sus excedentes y especializar los cultivos; por fin, con una producción preindustrial (artesanado textil) subordinada a la agricultura por el doble engranaje de la producción de materias primas y por el mecanismo recurrente de las crisis cíclicas de subconsumo industrial (Labrousse, Les structures et les hommes, Paris 1968). La diferencia era que en la Iberia húmeda (el caso gallego entre otros) éste último factor ejercía un peso menor que el subconsumo propiamente agrícola (autoconsumo de insuficiencia), por la mayor debilidad tanto de la agricultura como de la protoindustria con respecto a los países de monocultivo o de producción dual de trigo y lana, como Picardía, el Beauvaisis del norte o Tierra de Campos. Eso acabaría produciendo que las industrias locales del lino fuesen incapaces de evolucionar del nivel de mero artesanado rural al de protoindustria y acabasen desapareciendo (P. Saavedra, Mondoñedo, 1985).

\section{2/ Pierre Goubert}

a/ El Beauvaisis: tesis e historia total. Objeto.

b/ El Beauvaisis: Fuentes y critica de las fuentes.

c/ El Beauvaisis: métodos. Aritmética y modelos.

d/El Beauvaisis, un destino: el endeudamiento campesino. 
No menos indispensable para un programa de reciclaje del conocimiento en historia social era a la altura de 1970 la obra de Pierre Goubert, el discípulo de Jean Meuvret en la primera hora y más tarde de Labrousse, quien pocos años antes había publicado su tesis de Estado sobre el Beauvaisis (EHESS, 1960, 2 vols.), rápidamente agotada en Francia y que sólo pudimos conseguir de favor en fotocopia de los fondos de la M.S.H. parisina (una reliquia de museo que hoy se custodia en los despachos de la Facultad compostelana). Esta obra llevaba a la concreción un programa amplio de historia globalizada sobre la sociedad y modos de vida en un territorio bien dimensionado (el Beauvaisis, extremo meridional de Picardía, ca. 3.000 kilómetros cuadrados, 162 parroquias, unos cien mil habitantes en 1700, densidad 30, media de ca. 20 kilómetros cuadrados y de ca. 600 habs. por parroquia). Una gran tesis realizada con las pautas de precisión y modelización heredadas de ambos maestros, no sólo Labrousse sino también Jean Meuvret, especialista en las mercuriales y en la moneda y primer definidor de las crisis agrarias y demográficas “de tipo antiguo”. El Beauvaisis representaba entonces lo más próximo que se podía aspirar a la historia-total que preconizaba Febvre y brindaba el modelo historiográfico a seguir para los estudios de historia social e historia rural que por aquellos años se iniciaban en el noroeste peninsular, con un sentido de análisis global de alcance regional o comarcal. En ella se creía encontrar una síntesis de la completa renovación metodológica de la segunda generación de Annales, con su ampliación temática y metódica: nuevos objetos de estudio, aspectos o temas; nuevas fuentes durmientes; otros métodos nuevos de análisis.

La tesis de Estado de Goubert (EHESS, 1960, 2 vols.) llegaba precedida de anunciadoras primicias que no podían dejar de atraer la atención sobre el autor, como eran sus primeros trabajos sobre problemas demográficos publicados en Annales (desde 1952), en los que promocionaba la riqueza todavía inexplorada de los archivos parroquiales; sus primeros trabajos sobre temas de historia rural en la revista dirigida por Labrousse (Revue d'Histoire Économique et Sociale, $\left.\mathrm{n}^{\mathrm{o}} 1,1957\right)$, en donde daba a conocer la riqueza no menor de los inventarios post mortem para el estudio de las técnicas agrícolas y de otros diversos aspectos de la vida de la ruralía; o su puesta al día del concepto de mortalidad extraordinaria en su aportación al famoso congreso de Lieja (1963) sobre Problèmes de la mortalité (Liége, 1965, p. 79-92), 
en donde recuperaba el tema de las "mortalidades de crisis" tomado de su primer maestro Meuvret, para formular nuevos "problemas e hipótesis" sobre diferentes tipos de comportamiento del fenómeno a nivel espacial.

Meuvret-Goubert: Las crisis agrarias y demográficas de «tipo antiguo».

La influencia de la climatología en las cosechas, su repercusión en los precios de los cereales y su reflejo en la mortalidad extraordinaria o de crisis eran nociones familiares desde el trabajo de Jean Meuvret (Population, 1, INED 1946, $2^{\mathrm{a}}$ ed. 1971) que había acuñado el concepto tipológico de «crisis demográfica de tipo antiguo» y su expresión gráfica el "rombo de crisis" (gráficas de Dijon y de Rozoy-en-Brie). Su discípulo directo Pierre Goubert recuperaba el mecanismo del ideal-typus (gráficas de Saint Lambert-des-Levées, de Bresles y de Beaune-la-Rolande), estableciendo medidas y proporciones basadas en la correlación directa entre el precio del grano y el número de defunciones y la correlación inversa entre aquél y el número de concepciones. Pasada la crisis, la curva de los matrimonios remontaba "en flecha", a causa de las segundas nupcias de viudos, las concepciones se recuperaban con vigor y las defunciones disminuían, a causa de las muertes prematuras que la crisis se había cobrado a modo de anticipo, bajo forma de una «severa selección natural».

Detrás de estos trabajos franceses en los años ochenta llegarían de todas partes seguidores de esta observación, la mortalidad de crisis, fácilmente constatable en los registros parroquiales de defunciones de diferentes regiones de la Península Ibérica. Principalmente en Castilla, en la Mancha y en toda la España interior, en países de llanura fundados sobre la asociación trigo y oveja, como lo era la llanura picarda; esto es, en las áreas de monocultivo cerealero en donde el impacto de las crisis de mortalidad era más acusado y su repetición cíclica sería en parte responsable de la tardanza en salir de la larga crisis del siglo XVII.

Para algunas comarcas de Galicia y de Portugal el estudio había comenzado ya en los setenta, con resultados contrastados respecto a la meseta interior. De esos trabajos se desprendía que en la economía del maíz, como en Galicia y en el Minho portugués, las grandes mortalidades «catastróficas» de tipo beauvaisino o castellano, en las que la mortalidad ordinaria duplica o triplica y los matrimonios caían a cero, eran aquí excepcionales 
(apenas las de 1693-94 y de 1709-10); pero con frecuencia cíclica (unas 18 veces en dos siglos, entre 1609 y 1812) hacen su aparición las crisis «larvadas», en la terminología de Meuvret, en las que la mortalidad raramente sobrepasa en un cincuenta por ciento los niveles de la mortalidad ordinaria, aunque sí se acusa el efecto de las malas cosechas en el descenso del número de matrimonios y de concepciones, que en el marco del año-cosecha pueden caer a los dos tercios de su nivel ordinario o por debajo de eso en el marco trimestral (Eiras Roel, 1996, p. 87 passim).

Las crisis de 1693-94 y de 1709-10 van asociadas a fuertes lluvias de primavera y verano que frustran o pudren la cosecha de cereales de invierno; pero la más grave de las conocidas en el oeste atlántico (Galicia, etc.) y en el norte cantábrico fue la de 1768-69, una crisis agraria específica de la agricultura del maíz, al tener por causa una sucesión de veranos fríos y lluviosos que además de pudrir la cosecha del cereal de invierno impedían granar y madurar al cereal de primavera. La causa se atribuye a los «temporales contrarios», al «tiempo desigual y enfermo» (déficit térmico, lluvias prolongadas y tardías de primavera-verano) y suelen ir acompañadas de rogativas parroquiales ad impetrandan serenitatem que se eslabonan de primavera a otoño. Además de sus repercusiones demográficas, la crisis agraria de 1768-69 en todo el norte y oeste peninsular - y por extensión en todo el frente atlántico de la Europa templado-húmeda - ofrecía un testimonio excepcionalmente bien documentado de las condiciones termométricas y pluviométricas de las décadas centrales del XVIII, en abierto contraste con las del interciclo labroussiano de una década posterior (Eiras Roel, 1996, Ibidem).

\section{El Beauvaisis: tesis e historia total. Objeto.}

Naturalmente el Beauvaisis de Goubert era mucho más que crisis demográficas; incluso en ese mismo plano existían también las estructuras demográficas, la fecundidad, la mortalidad ordinaria, el reemplazo, detenidamente estudiadas. En esa tesis de historia-total sobre uno de los muchos países de Francia su autor enfrentaba un análisis de amplio espectro sobre la posición y condiciones de vida (habitat humano, composición familiar, propiedad, ingresos, productividad económica, recursos complementarios, endeudamiento, etc.) de los individuos dentro de su grupo social, preferente- 
mente los más humildes, los campesinos; aunque también se ocupaba de otros, como los obreros y los empresarios del textil (los Danse y los Motte beauvaisinos, estudiados en otros trabajos). Pero si algo definía el carácter de la obra y de su autor era la dedicación al estudio de los más humildes. Goubert pensaba como Labrousse que no hay verdadera historia que no sea historia social, y dentro de ella la de la pobreza resultaba ser la parte específica a privilegiar, por la buena razón de que en todo tiempo - y más todavía en los siglos modernos de los que el autor se ocupaba - es mayor el número de los pobres que el de los acomodados.

Aquí se deben subrayar sobre todo las aportaciones al estudio de la población rural, dejando en un segundo plano el estudio sobre la manufactura drapante y la sociología de la ciudad de Beauvais, tratadas en capítulos posteriores de la misma obra. Entre los aciertos, el empleo de los documentos catastrales (los "plans-terriers" de los señores laicos o eclesiásticos) y fiscales (los "rôles de tailles" o equivalentes) como base de partida para el estudio y clasificación de la jerarquía social y de la propiedad en el mundo campesino; haciendo realidad por vez primera (1960) la célebre llamada de Labrousse en el congreso de Roma (1955) sobre el empleo sistemático de la documentación catastral y fiscal para el análisis de la estructura social de campo y ciudad indistintamente.

A partir de ahí, la diversidad del mundo campesino y la realidad de la ruralía, las imponentes desigualdades de la población rural: una "infima minoría" de campesinos excedentarios que van a más, los laboureurs y algún gros fermier, auténticos intermediarios entre la gran propiedad absentista y el mundo rural. Y una aplastante mayoría de campesinos deficitarios que van a menos y se reproducen en la pobreza: los manouvriers, híbrido de jornalero y de pequeño propietario en equilibrio inestable, mezclados con los artesanos rurales y los puros jornaleros, todos mano de obra temporal. Los roles o cuadernos de la imposición facilitan la ventilación del número y proporciones de excedentarios y deficitarios en cada comunidad rural; los planes parcelarios de algunos señores y conventos permiten conocer la distribución de su propiedad para algunas parroquias concretas (como el de las monjas de Saint-Paul en Goincourt). Distribución tipo en una parroquia de unos cien "fuegos": "un par de ricos laboureurs o de gros fermiers; una veintena de campesinos "médiocres", pequeños propietarios y arrenda- 
tarios a la vez; unas cincuenta familias de manouvriers, el resto artesanos miserables o jornaleros sin nada propio" (Beauvaisis, p. $158 \mathrm{ss}$.)

El estudio goubertiano se completaba con los movimientos de doble dirección en el medio regional: del campo a la ciudad próxima, en la misma dirección en que marchaban las rentas y los excedentes del producto neto campesino; y de la ciudad al campo, en el mismo sentido en que viajaban las usuras y préstamos hipotecarios para remediar a corto plazo las necesidades de los campesinos depauperados o arruinados en años de cosecha deficitaria. La concreción de aquel conjunto de parámetros era fruto del manejo de gran número de fuentes, de la verificación de gran número de casos y del empleo de sutiles razonamientos, necesarios para la determinación de los rendimientos a la simiente y de la productividad por hectárea por ejemplo, que hacían de la tesis de Goubert otro clásico de la historia cuantitativa. Hasta aquí el objeto de la tesis de Pierre Goubert según la recensión que le dedicamos (HISPANIA. 121 (1972) 490-495).

El Beauvaisis: Fuentes y crítica de las fuentes.

El interés del Beauvaisis no se limitaba a su amplio repertorio de aspectos o temas sobre la sociedad de la época, principalmente rural. Atraía también por su poder de alumbrar todo un elenco de nuevas fuentes durmientes al servicio de la historia social y rural, con capacidad de aplicación a otros territorios: fuentes departamentales, municipales, parroquiales, hospitalarias y privadas, a algunas de las cuales ya se ha hecho mención. Los documentos catastrales y fiscales también mencionados para el estudio de la desigualdad de las fortunas; los apeos o "plans-terriers" realizados por los grandes propietarios para conocer la parcelación y situación de la propiedad raíz; los peritajes o "expertises" para los procesos de "surtaux" o recargo de impuestos, en los que el autor encontraba una increíble locuacidad. Destacaba el uso de fuentes notariales para los aspectos más diversos de la sociedad y las formas de la economía rural o urbana; contratos matrimoniales para el estudio de las afinidades y relaciones entre los grupos sociales urbanos; inventarios post mortem para conocer el utillaje y ajuar de los grupos rurales; ventas de tierras, contratos arrendaticios, instrumentos de crédito, cartas de préstamo, obligaciones y mohatras de crédito usurario, para seguir las causas y efectos del endeudamiento popular; ventas de tierras igualmente 
para observar los efectos confiscatorios del crédito usurario sobre la pequeña propiedad campesina y otras hasta cubrir toda la rica tipología de las fuentes notariales. Descubría además otras vetas documentales importantes, como las contabilidades eclesiásticas y hospitalarias, los papeles de sucesión en los archivos de las justicias señoriales para valorar por grupos sociales la importancia de los legados, etc. etc. Para las condiciones de vida del menu peuple de la ciudad de Beauvais y el mundo de los tejedores, Goubert extendía el elenco de fuentes a las encuestas de policía sobre el número de obradores y el reparto desigual del número de telares, las declaraciones de los maestros pañeros sobre el número de tejedores o peinadores de cada uno (no así de las hilanderas, que no figuran), y los contratos de aprendizaje que informan sobre los "salarios" y el reclutamiento de los aprendices del textil. Los archivos hospitalarios de Beauvais suministraban información necesaria para el estudio de la evolución coyuntural y en materia de precios y salarios. Otras instituciones asistenciales, como los registros hospitalarios del Hotel-Dieu y del Bureau des Pauvres, acercaban al historiador al corazón de la pobreza. ${ }^{14}$

Pero tan importante como la variedad de las fuentes alumbradas era en este autor la crítica de la fuente de archivo: crítica de intencionalidad, crítica de veracidad, crítica de representatividad, crítica de registro. Sus reservas se aplicaban con especial rigor a las omisiones y lagunas en el caso de los archivos parroquiales (subregistro o infrarregistro). Pero en algunos de sus trabajos no perdona tampoco las cautelas a adoptar con los documentos notariales (los inventarios post mortem entre ellos), "incompletos

\footnotetext{
${ }^{14}$ Sobre este tema de la pobreza, de la mediocridad e insuficiencia del mundo campesino o de la pobreza asistida en la ciudad próxima y sus variantes regionales, a la altura de 1973 existían ya otros autores a seguir, como Jean-Pierre Gutton (1971) o los autores de grandes tesis regionales francesas, de René Baehrel (1961) sobre la baja Provenza a Abel Poitrineau (1965) sobre la baja Auvernia, no mucho después a Jean Jacquart (1974) sobre la cuenca parisina, a Guy Cabourdin (1977) sobre la Lorena o a Jean Nicolas (1978) sobre Saboya, etc. y a sus discípulos ruralistas franceses o ibéricos; en todos los cuales el marco de estudio eran las economías familiares de subsistencia bajo el signo de la escasez y la insuficiencia para la reproducción del capital social al ritmo de reproducción del capital humano. Pero todos ellos eran posteriores a la obra de Goubert e influidos por ésta de algún modo. En los años sesenta la atención se focalizaba en Pierre Goubert y luego en el Languedoc.
} 
con frecuencia, poco sinceros a veces", cuya representatividad social discute ya que suelen excluir al campesinado más pobre. ${ }^{15}$

\section{El Beauvaisis: métodos. Aritmética y modelos.}

En el plano de los recursos de método, el principal logro de Goubert nos parece haber sido la adopción de sencillos modelos aritméticos para razonar el funcionamiento de la realidad social comprobada en el pasado como en el presente, que en su caso se inspiran en otros ejemplos anteriores de Labrousse y de Meuvret, aunque también reciben la influencia del método del modelo postulado por entonces (ca. 1960) por los filósofos y epistemólogos estructuralistas, y que años después sería igualmente adoptado con fortuna por algunos portaestandartes de la historiografía polaca (Jerzy Topolski, Witold Kula). Los modelos aritméticos de Goubert son sencillos recursos explicativos que reposan sobre los resultados de la investigación documental; sin previa experimentación (documentación de archivo) y medición de los hechos no habría modelo. Los valores cifrados de los parámetros necesarios para razonar los hechos básicos de la población o de la economía (como las proporciones entre los grupos sociales y sus atributos, la propiedad, la explotación, los recursos, la renta, las cargas) suelen expresarse en porcentajes sencillos. En la integración funcional de esos parámetros radica el valor explicativo del modelo, un recurso pedagógico para entender el carácter regular y socialmente racionalizado de lo que a primera vista se presenta como hechos de azar discontinuos.

\section{A/ El modelo demográfico de Auneuil}

Goubert aplica sus modelos a razonar los comportamientos de la población, de la economía rural de subsistencia, de las cargas sobre el productor y del autoconsumo campesino, entre otros. En materia de

${ }^{15}$ GOUBERT, Pierre - Les techniques agricoles dans les pays picards aux $17^{\mathrm{e}}$ et $18^{\mathrm{e}}$ siècles, R.H.E.S., 1957. A pesar de la crítica utiliza los inventarios siempre que le es posible y los considera en primer lugar entre las fuentes que hablan del campesinado. Por lo que se refiere a la postura crítica a adoptar, comprobaciones a realizar y cautelas a tomar frente a los libros parroquiales de defunciones, etc. es aconsejable prestar atención al rapport presentado por el autor a las Jornadas de 1973. "Los registros parroquiales son documentos históricos a criticar... y no máquinas de suministrar automáticamente datos cifrados”. GOUBERT, Pierre - Histoire démographique, Actas IJ. M.H.A., III, Historia Moderna, 1973 (1975), p. 253-273. 
población el hecho de base que se trata de explicar en sus claves internas demográficas, es el escaso o nulo crecimiento de la población del Beauvaisis (como en otras regiones de Francia o de la Península ibérica) en todo el siglo XVII y hasta el cambio de trend a partir de 1730. Goubert lo razona con el sencillo modelo de Auneuil (1656-1735), construido a partir de los hechos vitales sacados de los libros parroquiales pertenecientes a todas las mujeres nacidas en la localidad en ese período, y lo expresa en un índice sintético representativo comparable en el espacio y en el tiempo: la tasa de reemplazo generacional o tasa neta de reproducción (T.N.R.) que Goubert toma del demógrafo Adolphe Landry (1934). El modelo demográfico de Auneuil se funda en la combinación de cinco parámetros determinantes: 1) celibato femenino, 2) edad de la mujer al matrimonio, 3) período de fertilidad de la mujer, 4) duración de los intervalos intergenésicos y 5) duración del matrimonio. Estos cinco factores determinan la media de hijos por unión, miden la fecundidad y en último término la natalidad. La natalidad, junto con la mortalidad infantil y juvenil de la mujer antes del matrimonio y con el porcentaje de celibato, determinan a su vez la tasa de reemplazo generacional, apenas superior a la unidad en este caso (Auneuil 1656-1735: TNR 1,03), lo que significa ausencia de crecimiento en este período. El crecimiento, si lo hay, no basta para prever los riesgos de una "mortalidad" extraordinaria o de crisis. Después de 1740, charnela de la última gran crisis de 1741-43 en Francia, la crisis demográfica desaparecerá o se hará menos marcada en las curvas ("disette larvée"), lo que provocará el excedente casi constante de los nacimientos sobre las defunciones y con ello el cambio de régimen demográfico (Beauvaisis, p. 25-84). ${ }^{16}$

${ }^{16}$ La tasa de reemplazo, apenas ligeramente superior a la unidad $(1,03)$ en ese período, expresa la débil capacidad de reposición de efectivos de la población del Beauvaisis en la segunda mitad del XVII y su estancamiento en un precario equilibrio demográfico. Los datos experimentales se toman de las fuentes parroquiales de la localidad de Auneuil (1656-1735). En ese período de 438 mujeres madres nacen 2.127 hijos (de ellos 1.037 niñas y 1.090 niños); a la edad de 20 años llegan sólo 1.040 (de ellos 528 muchachas y 512 muchachos); con una tasa de celibato próxima al 15 por ciento llegan al matrimonio 451 futuras madres; ergo T.N.R. insignificante de 1,03 (Beauvaisis, p. 41-44). Otro ejemplo quizá mejor ajustado de la aplicación del modelo Auneuil de reemplazo poblacional, tomado de otro autor y aplicado a otra región de Francia. Trabajando a partir de fichas reunidas por J.-C. Polton para la localidad de Coulommiers (1670-1715), Jacques Dupaquier recalcula sobre el modelo de Auneuil la tasa de reemplazo en la región de París en época de Luis XIV. Reemplazo: de 130 


\section{B/ El modelo económico de economía rural de subsistencia}

Aplicado al funcionamiento de la economía rural de subsistencia, el método del modelo se funda en la verificación documental previa de los valores de los cuatro (o cinco, o seis según los casos) parámetros necesarios para razonar el funcionamiento de la economía rural, a saber: 1) el cálculo de la producción estimada del campesino medio en función de las superficies de cultivo y de los rendimientos; 2) el cálculo de las necesidades mínimas de autoconsumo de la familia campesina (a razón de cuatro hectólitros de grano por persona y año, mínimo de dos libras de pan por persona y día, la ración fisiocrática recuperada por Labrousse); 3) el peso y las formas de la detracción del producto neto del campo a la ciudad o a la Abadía por las cuatro vías de la renta, el diezmo, la talla y los derechos señoriales; 4) el cálculo de la capacidad o no del campesino medio de producir excedentes negociables para su reproducción de equipo; y todavía 5) el cálculo de la capacidad global del territorio de generar excedentes (negociables o de otro tipo) con destino a la ciudad próxima (Beauvaisis, p. 104-105, 158-165, 180-185).

En régimen de assolement triennal y en el territorio estudiado, para asegurar el sustento de su familia y demás cargas el campesino debía cosechar al menos 40 hectólitros de trigo sobre la primera hoja, dejando la segunda para leguminosas y sobrecosechas reservadas al ganado y la tercera al barbecho. « Esto supone que por debajo de 10 hectáreas de tierras ningún campesino podía cosechar el pan de su familia, por abundantes que fuesen las cosechas... En año mediocre (relación 10/22), 40 hectólitros requerirían una explotación de 20 hectáreas. Raros eran los labradores que alcanzaban esta última cifra ». En año malo incluso ese buen labrador estaba condenado a endeudarse. «Y sin embargo esos campesinos que teóricamente no podían vivir de

madres de familias completas de Coulommiers (1670-1715), han nacido 617 hijos, de ellos 316 hijas; de las cuales 151 viven todavía a la edad de 20 años. Con una tasa de celibato de 10 por ciento llegan al matrimonio 136 muchachas. Admitiendo un cociente de mortalidad femenina de 100 por mil entre 20 y 30 años, edad media probable a la maternidad, quedan 122 futuras madres para reanudar el ciclo: ergo TNR negativa de 0,938. « La T.N.R. cae a 0,938 . En ausencia de inmigración, la población de Coulommiers estaría pues condenada a decrecer (y eso es justamente lo que nosotros hemos observado) ». DUPAQUIER, J. - Villes et villages de l'Ancienne France. ADH. 1969, p. 26. 
sus tierras, han vivido. Han vivido, aunque endeudándose » (Beauvaisis, p. $180-182){ }^{17}$

Elementos de ese modelo son también las detracciones del producto neto campesino que se deben a la simiente y los que podemos llamar excedentes compulsivos, dado que no son negociables o directamente comercializables por el productor mismo; salen de la comunidad campesina en forma de prestaciones paisanas gratuitas y forzosas al señor, al rey, al dueño de la renta o al arrendatario de los diezmos. Expresadas en porcentaje sobre la producción del campesino medio retienen: la simiente un 16 por ciento; la « talla » no menos de otro 16 por ciento; el diezmo no menos del 8 por ciento; el arriendo de al menos una parte de las tierras del 6 al 10 por ciento; « aide, gabelle y champart» en torno a otro 10 por ciento. Sumado todo, supera el 56 por ciento; en el mejor caso le queda al campesino sólo el 44 por ciento de la cosecha; guardaba para sí « en el caso más frecuente, el del pequeño propietario que explota a la vez sus tierras propias y algunas en arriendo, entre el tercio y la mitad» (Ibid. p. 182).

Los excedentes que llamamos compulsivos dominan la última articulación del modelo goubertiano que es la capacidad del territorio de generar « excedentes » para el abasto urbano. Goubert aplica el mismo esquema de modelización a la estimación de la producción y el consumo del campo y la ciudad. Según su estimación, una vez atendidas las necesidades del autoconsumo y la reproducción de la simiente, un tercio de la cosecha del Beauvaisis serían excedentes negociables para el abasto de la ciudad próxima (el Beauvaisis, cien mil habitantes, tres tercios; Beauvais ciudad, 14.000 habitantes, un tercio de la

${ }^{17}$ En el Beauvaisis los resultados de archivo arrojan una tasa de simiente de 1,25 a 1,5 quintales la hectárea « igual que hoy » y una producción de trigo de 12 a 15 quintales por hectárea en año normal, ergo rendimientos a la simiente de 6 por 1. Goubert construye su modelo económico sobre la base de un campesino " mediòcre » (tipo haricotier) que cultiva 4,5 hectáreas de tierra propia y otra tanta en arrendamiento. Produce pues en año normal unos 36 hectólitros de trigo sobre la primera hoja ( 3 hectáreas en assolement triennal). Para sostener las necesidades del autoconsumo de una familia de cinco miembros necesita unos 20 hectólitros. Para hacer frente a los gastos de reproducción y a las cargas u obligaciones fijas de la simiente (6 hectólitros), la talla (otros 6), el diezmo (al 8 por ciento, 3 hectólitros), « champart » y renta de la tierra representarían no menos de otros 4 hectólitros, y quedan todavía otras obligaciones fijas con el cura, el maestro, el herrero. Sumado todo, necesitaría no menos de 40 hectólitros de grano, más que la producción de la primera hoja. Incluso en año bueno, debía echar mano de algo de avena u otro producto de la segunda hoja, reservada a las leguminosas y al ganado (Beauvaisis, p. 165 ss.). 
cosecha ?). El cálculo de la producción puede ser optimista, pensamos, al incluir lo de la segunda hoja, no destinada a los cereales de invierno. Con esa salvedad, y como modo de operación que puede ser retocado por tanteos, su modelo sirve como ejemplo para integrar esos « excedentes » compulsivos en la parte de la producción campesina que - comercializada o no por el productor - acaba siendo destinada al abastecimiento urbano. ${ }^{18}$

\section{El Beauvaisis, un destino: el endeudamiento campesino.}

En el discurso histórico de P. Goubert el tema de los excedentes (compulsivos) está a su vez directamente relacionado con el universal endeudamiento campesino, como una de sus causas, al lado de las necesidades del autoconsumo familiar y de la reproducción de la simiente y ganado. Una ínfima minoría de campesinos excedentarios y una gran mayoría de campesinos deficitarios, al menos en año malo o de cosecha floja. A través del mecanismo de la deuda y de sus figuras jurídicas reflejadas en la documentación notarial, los mediocres acaban siendo expropiados de sus pequeña parcelas en beneficio de sus vecinos más poderosos, aunque no sólo de ellos; pueden serlo también en beneficio de los ricos burgueses de la ciudad próxima. El esquema modelizado para el Beauvaisis conduce inexorablemente al empobrecimiento y su corolario el endeudamiento.

${ }^{18}$ Goubert hace sus cálculos sobre una muestra de 20 parroquias picardas estudiadas $(2.100$ fuegos, ca. 8.500 habs.), que cuentan unas 25.000 arpentas de tierra laborable ; a razón de 0,51 Has., dan 12.750 Has. de tierra laborable en las tres hojas. Adaptamos aquí su modelo :

20 parroquias : 25.000 arpentas de tierra laborable, 8.300 arpentas la $1^{\mathrm{a}}$ « hoja del pan ».

20 parroquias : 16.666 arpentas de cultivo en dos hojas, dan 8.500 Has. de cultivo anual.

20 parroquias : 8.333 arpentas x 0,51 Has., dan 4.250 Has. la $1^{\mathrm{a}}$ « hoja del pan ».

20 parroquias : 8.500 has./2.100 fuegos, dan 4 Has. por cultivador en las dos hojas.

En año bueno, rendimiento medio de 6 por 1, equivalen a 9 quintales la hectárea.

Deducida simiente (1/6) y censos (mínimo 1/6), quedan al cultivador 6 qq./la Ha.

(Las demás detracciones son excedentes compulsivos, destino también la ciudad próxima).

20 parroquias : 8.500 Has. Producto 8.500 por 6, dan 51.000 quintales (en 2 hojas).

Consumo : 4 quintales por persona/año x 8.500 habs., dan 34.000 qq. para autoconsumo.

Producto 51.000 qq.; autoconsumo 34.000 qq.; excedente « negociable » 17.000 qq.

«Salvo error, sobra con que alimentar unos 4.000 étrangers; el tercio de la cosecha era negociable ». «En los años favorables el consumo de la ciudad absorvía el excedente del campo. En los años de escasez los pobres morían por igual ». (Beauvaisis, p. 104-105). 
De ahí que el personaje central que domina la obra sea el espectro de la deuda campesina y las transferencias de propiedad que la culminan.

P. Goubert enumera los diferentes motivos y categorías del endeudamiento campesino y como las deudas a corto plazo acaban transformadas en obligaciones hipotecarias o « constituciones de renta ». Los motivos eran variados: deudas con los artesanos, el pastor o el maestro; deudas con el labrador rico o el « gros fermier » por alquiler de yuntas o arados, por adelanto de semillas, por dinero prestado; deudas por atrasos en el pago de rentas que se acrecían en los años malos. De rebote, una nueva carga, una nueva detracción se sumaba a las anteriores. Cuando el campesino no podía seguir haciendo frente a las cargas, quedaba la expropiación de una de sus parcelas en beneficio de su acreedor de la ciudad próxima, el burgués rico, o de la misma aldea, el paisano rico, el « gros fermier ». « En los grandes años de miseria, la deuda campesina se inflaba en proporciones prodigiosas que se reflejan todavía en el volumen de los mismos protocolos notariales ». Goubert compara el espesor de las minutas del mismo notario en un año de precios bajos y en un año de precios altos de los cereales: « la razón va del simple al doble, o al triple ». De este modo el endeudamiento progresivo de la mayoría de los vecinos de la aldea está en el origen de las haciendas de los villanos ricos (Beauvaisis, p. $183-185) .{ }^{19}$

\section{3/ Emmanuel Le Roy Ladurie}

a/ En Languedoc. La relación dialéctica entre población y propiedad. b/ En Languedoc. La tensión dialéctica entre población y recursos.

c/ Más allá del Languedoc. La parte del clima.

d/ Más allá del Languedoc. La parte del diezmo.

${ }^{19}$ Los modelos aritméticos de inspiración labroussiana con los que trabajaba P. Goubert eran sencillos y compuestos a base de un corto número de elementos. A comienzos de la siguiente década y de la mano de los historiadores polacos llegarían otros modelos más complejos y elaborados (integrando un mayor número de elementos), aunque igualmente seductores por precisos, claros y comprensibles. Su inconveniente es que por instrumentar la economía del gran dominio señorial de la Europa oriental y sobre fuentes específicas de esos grandes dominios, en explotación directa para el mercado, no se adaptan a la agricultura de pequeño cultivo de la Europa occidental y meridional. Sobre el más importante de esos ejemplos, el libro de Witold Kula (Paris, Mouton, 1970) y su modelo de economía señorial polaca, remitimos a nuestra ya citada recensión en HISPANIA. 119 (1971) 659-671. 
Algunos años después del Beauvaisis llegaría el Languedoc de Emmanuel Le Roy Ladurie (Paris, SEVPEN, 1966) quien, trabajando en paralelo con Goubert pero a distancia y sin ninguna posibilidad de influirse recíprocamente, redundaría en algunos hallazgos que ya nos son conocidos; como el valor de los documentos notariales de los departamentos del Gard y del Hérault como fuentes para la vida rural: los contratos de arriendo y de "métayage" (aparcería) para el estudio de las técnicas agrarias, del instrumental agrícola, de las servidumbres colectivas, etc.; los inventarios post mortem para los útiles de cultivo («l'araire, la herse, la faux, la faucille »), el ganado, las reservas de cosecha y estiércol, etc. etc. Un ejemplo más y magistralmente construido de la influencia vidaliana y febvriana sobre la adaptación o acomodación entre el hombre y el medio que distinguía a la nueva historia de los paisajes agrarios. El valor añadido de la nueva tesis sobre los campesinos languedocianos no estaba sin embargo en eso sino en otras innovaciones más conceptuales, como las relaciones entre desarrollo agrario y crecimiento demográfico en una población preindustrial mediterránea o las interrelaciones mutuas pero de signo contrario entre población y propiedad del suelo o entre el crecimiento de la población y la acomodación a los recursos.

Emmanuel Le Roy Ladurie, tesis. La relación dialéctica entre población y propiedad.

Lo que Labrousse había significado para entender las oscilaciones en el tiempo corto de las fluctuaciones estacionales o cíclicas, lo significaba el Languedoc (1966) para entender los movimientos y cambios en el tiempo amplio de la larga duración secular. Comenzando por los movimientos de la población, que parece ser junto con el clima la caja de cambios que dirige la marcha. El estudio de Le Roy Ladurie sobre la evolución de la población en su espacio mediterráneo y sus causas determinantes integraba los movimientos de la población pechera (registrada en los libros de la talla) con los de la propiedad de la tierra y la contradanza de concentración/ /desmembración de la propiedad (puntualmente reflejada en los compoix del país, matrices catastrales que registraban la propiedad parcela a parcela); dos tipos de fuentes que en ambos casos se remontaban al siglo XV en los archivos languedocianos. 
A través del diagrama de la propiedad así reconstruido, una sucesión de fases seculares o intraseculares se diseñaba, en función del número de aspirantes a una porción de tierra propia por pequeña que fuese: en fase de expansión demográfica el número de minúsculos propietarios aumentaba vertiginosamente mientras la propiedad se atomizaba. En la fase siguiente, cuando la recesión demográfica diezmaba de modo sostenido los pequeños tallables, la propiedad se reagrupaba durante un siglo o cosa así. El siglo XVI prolongado en buena parte del XVII (hasta 1630 al menos, hasta 1670 tal vez en algunos lugares), la segunda mitad del XVIII prolongada en los dos primeros tercios del XIX, eran fases de démembrement de la propiedad en la Francia mediterránea. La segunda mitad del siglo XV, las décadas finales del XVII y la primera mitad del XVIII eran fases de rassemblement de la propiedad, según el testimonio inapelable de los compoix; todo lo cual se corresponde con una versión mediterránea del crecimiento de la población en sentido inverso al de la concentración de la propiedad.

Las décadas que preceden a la Revolución, y las que la siguen, habían sido tiempos de crecimiento auténtico en el Languedoc, crecimiento real del producto interior bruto: las curvas diezmales del producto bruto de la agricultura igualan o superan las del crecimiento de la población; los salarios mantienen su poder adquisitivo en este espacio singular, a contrapelo de la Francia del norte y de los enclaves del textil. Más tarde, la última fase del crecimiento demográfico galopante y de la extrema desmembración parcelaria en el Languedoc se había visto estimulada, empujada o arrastrada por la viticultura de mercado, que multiplicaba los ingresos por setérée cultivada y permitía la conversión del antiguo labriego en cultivador de mercado. El paysan tradicional del policultivo y la agricultura de subsistencia (autoconsumo familiar) daba paso al orondo viticultor en monocultivo para el mercado, cuyos ingresos le permitían comprar su alimento cotidiano. Pero el sueño decimonónico de la viticultura de mercado finalizaba de golpe con el desastre de la filoxera (en 1870-1873) y los comienzos del éxodo rural. ¿Resucitan en ese momento las maldiciones maltusianas que habían dominado el Languedoc de los siglos XVI-XVII, o como afirma el autor, "Malthus llegaría demasiado tarde"? (Paysans de Languedoc, p. 367-370; citamos por la edición comercial de Flammarion, 1969.). 
Le Roy Ladurie. La tensión dialéctica entre población y recursos: una coyuntura social secular.

En el estudio sobre el Languedoc es la evolución de la población la fuerza de la naturaleza que lleva la danza, con repercusión tanto sobre la estructura de la propiedad (fraccionamiento o reagrupación de parcelas y heredades, desmembración minifundista o predominio de la propiedad media) como sobre el hábitat humano, el paisaje agrario, la composición familiar, el régimen de arrendamientos, el nivel de los salarios y finalmente sobre el régimen alimentario.

Con el estiaje humano de la primera mitad del siglo XV ("el siglo del hombre raro") se produce el abandono de tierras marginales, la extensión del bosque, del viñedo y del praderío a costa del labradío, la recuperación de la garriga y la aparición de despoblados, la revancha de una naturaleza silvestre y lujuriosa sobre las grandes roturaciones del período precedente. La abundancia de suelo cultivable produce la reagrupación de los linajes en formas de familia extensa, de familia patriarcal o de consorcios entre hermanos que viven sobre la tierra común, los affrèrements o fréreches. Los arrendamientos pierden valor ante la oferta de tierra cultivable; el colono dicta la ley al propietario, las rentas bajan con predominio de las rentas a canon fijo sobre las fórmulas de aparcería o de cultivo al tercio. Se eleva el poder adquisitivo de los salarios en dinero y la cuota del "salario gavilla" pagado en porción de la cosecha; el salario-ración mejora en calidad o en poder nutritivo; aumenta en general el consumo de carne en la mesa del campesino; caza y leña abundan para él (Paysans..., p. 13-56).

Con la recuperación demográfica del XVI los hombres se multiplican en los libros de la talla "como ratones en un granero"; los brazos sobrantes se lanzan al asalto de los yermos y terrenos roturables de las garrigas. Ampliación de las roturaciones de cereal a expensas del bosque, del viñedo, del matorral y del ganado. Doble respuesta al incremento de bocas y de brazos. Respuesta "extensiva": las roturaciones marginales de "novales" y las "rompudes" de las garrigas, roturaciones predativas del árbol y del suelo. Respuesta "intensiva": la arboricultura en cultivo promiscuo de frutos grasos (olivo, almendro y nogal sustituyen al encinar y al matorral) para compensar en la dieta el consumo de carne y grasas animales por el descenso de la ganadería menor (el cordero y el cerdo), provocado por la disminución de 
pastos y el retroceso del encinar. A cambio, sacrificio del viñedo, "hijo de la demografía menos exigente del siglo anterior", ante el hambre de granos. Stop a la vista a este tipo de crecimiento: no más tarde de 1560 la expansión cerealera va a detenerse al superarse el límite de rentabilidad de las nuevas roturaciones sobre suelos flojos o débiles, garrigas pedregosas que tal vez sólo duplican la simiente: aparece la ley de los rendimientos decrecientes, El producto diezmal, expresión de la renta de la agricultura, deja de crecer, mientras la población sigue creciendo. El equilibrio entre población y recursos alimentarios comienza a romperse; se abren para el Languedoc las famosas "tijeras" malthusianas (Paysans ..., p. 57-92).

Pérdida de productividad del trabajador del campo, pérdida de poder adquisitivo del salario, pérdida de calidad sino de cantidad de calorías en la dieta: es el deficiente balance de la expansión languedociana del XVI. El olivar aumenta pero menos que el número de bocas; la carne y el viñedo disminuyen. La masa de la producción agrícola en el XVI está volcada en la producción de alimentos energéticos y pobres, hidratos de carbono preferentemente (granos, castaña). He aquí la tesis de fondo del neomalthusianismo laduriano, según la cual la deflación humana tras las crisis del siglo XIV y del XVII va seguida de concentración parcelaria, recuperación espontánea del medio ambiente y aumento de bienestar para los que logran sobrevivir. Mientras que el crecimiento demográfico del XVI (no tanto el del XVIII?) se acompaña de fragmentación parcelaria y disminución de la productividad per capita, elevación de las rentas y caída del salario real, descenso del poder adquisitivo, pauperización de la dieta y de la nutrición en prótidos para los jornaleros del Languedoc, etc. Una historia dinámica con sentido vivo de la coyuntura y de la desigualdad de los tiempos, en la que se integra esa «dialéctica de la felicidad y la desgracia» que acompaña o sigue a las grandes mortalidades del siglo XIV y del siglo XVII, al permitir a la generación superviviente disponer en abundancia de tierras de cultivo y de pasto e incrementar la productividad del trabajo humano y de las bestias de labor, en perjuicio entonces de la renta dominical y de las prestaciones señoriales.

\section{Emmanuel Le Roy Ladurie, la parte del clima.}

Por aquellos años setenta el predicamento intelectual de Emmanuel Le Roy Ladurie en el campo de la historia rural procedía en parte de su gran 
tesis sobre el Languedoc, en parte también de otros trabajos que nos eran familiares, como su Histoire du climat depuis l'an mil (Flammarion, 1967). Este libro de 1967 sobre el clima seducía al historiador por penetrar en un terreno inexplorado y que a otros nos era inaccesible, aunque sí necesario para comprender y explicarnos las fluctuaciones de la climatología y con ello de la agricultura. Su autor demostraba las posibilidades de la ciencia histórica de adquirir los métodos y los materiales de trabajo para estudiar las variaciones del clima en la larga y media duración, poniendo a contribución para ello una variedad de métodos (dendrológico observado en los anillos de los árboles; fenológico documentando en los archivos las fechas estacionales de la floración vegetal (vendimias); geológico centrado principalmente en el estudio de las regresiones y transgresiones de los glaciares alpinos (con ayuda del C-14); arqueológico e histórico, asociado al anterior para localizar y datar las huellas de posible hábitat humano engullido por la lengua del glaciar; y otros como el estudio de las manchas solares que se conocían desde mediados del XVII. A lo que se añadían noticias descriptivas sobre hambres y pestes, buenas y malas cosechas, inundaciones y sequías (rogativas ad petendam pluvial o ad impetrandam serenitatem), etc.

Así Ladurie construía en historiador sus capítulos sobre los glaciares alpinos (1550-1850) y sobre el recalentamiento térmico del período 1850-1950 empleando también fuentes literarias y documentales (archivos locales y eclesiásticos, diocesanos y parroquiales de Grindelwald y otras localidades suizas); todas conjugadas para observar la historicidad y variabilidad del clima a lo largo del último milenio, desde el enfriamiento que se registra a partir de 1550 hasta el recalentamiento térmico que comienza a hacer sentir efectos claros en la glaciología a partir de 1850. Con esa diversidad de recursos, el estudio de Ladurie sobre los glaciares alpinos (el glaciar saboyano de Chamonix, el bernés de Grindelwald y otros) lograba reconstruir sobre el terreno la cronología y efectos de la progresión glaciar del período 1550-1850 (primera fase intensa la transgresión glaciar de ca.1546-ca.1644, perceptible en Saboya y en el cantón bernés en Suiza) y la regresión glaciar del período 1850-1950, sin perder de vista sus efectos sobre las cosechas reflejados en los procesos de diezmos. La regresión glaciar de la época contemporánea era observada de visu sobre el terreno (como en Chamonix-Argentière o en Saint-Gervais y en La Mer de Glace) por la distancia de uno 
o más kilómetros que media hoy entre las lenguas terminales de los frentes glaciares remanentes y el emplazamiento de las aldeas desaparecidas o de las edificaciones alcanzadas por la progresión glaciar del siglo XVI, que según los relatos de la época y procesos de diezmos barrió y engulló tierras centeneras, junto con las últimas casas de las aldeas más extremas, cruceros o capillas en ocasiones y docenas de cabañas de campesinos. En otros puntos, como en el bosque fósil de Grindelwald, el testigo de las grandes oscilaciones climáticas a lo largo de la historia es la presencia actual en medio del hielo o de las morrenas de troncos fósiles de árboles petrificados a altitudes en las que no existe otra huella más reciente de vegetación arbórea (Climat..., 1967, p. 102-134).

Este libro sobre la historia del clima nos informaba sobre los efectos de la llamada oscilación de Fernaud y en general sobre los grandes ciclos de las fluctuaciones de la climatología, la aridez y las precipitaciones. La fase intersecular de avance de los glaciares alpinos que comienza a principios de la Edad Moderna, después de dos siglos de retroceso glaciar a finales de la Edad Media, y que recibe el nombre de «pequeña edad glaciar», era un episodio a poner en relación con las catástrofes agrícolas y humanas de finales del siglo XVI en la Península ibérica y fuera de ella (tanto en Galicia y Asturias como en Andalucía, y tanto en la Francia del norte como en la Italia del sur), estando la causa última en fuerzas de la naturaleza que escapan al control de historiador. Era una invitación a considerar con alcance general el efecto de las oscilaciones climáticas sobre la producción agraria y, a partir de ahí, las relaciones entre producción y población en la larga y media duración. ${ }^{20}$

Los trabajos de este autor sobre el clima y su relación con la agricultura prestaban atención combinada a los dos vectores de temperatura y humedad;

${ }^{20}$ De este libro de Le Roy Ladurie sobre la climatología (1967), sobre la oscilación de Fernaud y la pequeña edad glaciar de mediados del XVI a mediados del XVII, nos valimos más tarde para tratar de explicar las relaciones entre producción agraria y población a nivel español, en una sesión de trabajo de la CIDH, celebrada en el congreso de Stuttgart (1985). En ese mismo trabajo y sesión integramos la tesis, tomada del Languedoc mediterráneo del mismo autor, de los rendimientos decrecientes como cuello de botella y freno factual a los incrementos de productividad en la Iberia seca, en ausencia de todo regadío para los cereales de invierno. Public. in FAUVE-CHAMOUX, A. - Évolution agraire et croissance démographique. Liège: Ordina Éditions, 1987, p. 23-30 y 113-122. 
aunque esto más bien en relación con los climas de la Francia templada y húmeda, como la región de París, gran productora de trigo. En relación con ese cuadrante climático, la tesis que parecía desprenderse (y que extendemos también al norte y noroeste peninsular) era que, en relación con la producción agraria, mientras en la Europa nórdica lo esencial es la temperatura, en la Europa oceánico-templada lo esencial es la humedad. En la Europa nórdica es la secuencia de años muy fríos en los que las simientes se congelan lo que causa las hambres de la Escania sueca o de Finlandia (los temibles «años verdes» de 1596-1602 ó de 1740-42, en que el trigo no madura y se pudre por el pie); mientras en la Europa oceánico-templada lo que cuentan son las precipitaciones y no es el frío ni la sequedad lo que produce las grandes calamidades, sino el exceso de lluvias que anegan las simientes o pudren las mieses, salvo casos raros de episodios de aridez estival, como las malas cosechas en torno a la década de 1620 en la Iberia seca (Castilla) ó de fríos extremos como los de 1709 ó de 1789 (en la Francia del norte). En el noroeste marítimo de Francia las cosechas resultan buenas cuando el invierno es frío y seco e incluso en Inglaterra una sequía estival puede ser un factor favorecedor de altos rendimientos de los cereales; lo temible en todo este espacio atlántico son las lluvias estivales persistentes que causan los veranos «podridos». «En la Europa oceánica y templada es el invierno lluvioso, la primavera fría y húmeda, el verano trempé pasado por agua, es decir, la recurrencia de los años húmedos lo que representa el principal peligro» (Le Roy Ladurie, Climat..., 1967, p. 280 passim).

En una óptica más general, uno de los efectos positivos del estudio del clima es que habituaba al historiador a superar la óptica estrecha de la corta duración para situarlo en las perspectivas de la larga duración secular (del período 1550-1850, como en este caso): en esto Le Roy Ladurie daba un paso más allá de Labrousse, y por todo eso y más todavía nos interesó confiarle la ponencia de historia rural para las jornadas de 1973.

\section{Emmanuel Le Roy Ladurie, la parte del diezmo.}

Había mucho más todavía, y era el protagonismo de Le Roy Ladurie al frente de la encuesta nacional francesa sobre la documentación diezmal y la dirección metodológica de tan importante encuesta que entonces acababa de entregar sus resultados (Cf. Les fluctuations du produit de la dîme..., Paris, 
Mouton, 1972; 396 p.). Esa primera encuesta de 1969 sobre la fuente diezmal en todas las regiones de Francia combinaba el método "directo" de empleo de los diezmos en especie a partir de los libros de tazmías parroquiales o monásticos (el sistema de percepción predominante tanto en la Francia del Midi como en Castilla, en Murcia o en la Andalucía occidental y penibética) con el método "indirecto" de diezmos arrendados en dinero y deflactados a partir de arrendamientos diezmales (el sistema de percepción predominante tanto en el Cambresis, en el Lyonnais o en la región walona de Namur como en Galicia o en Tibães).

De los diversos libros de Le Roy Ladurie, serían las orientaciones metodológicas contenidas en las Fluctuations du produit de la dîme (1972) lo que antes tendría aplicación en la Península ibérica, por razones de circunstancias tan oportunas como la inmediatez de la aparición de esa obra a la organización de las jornadas de 1973. El marcado predominio - lo mismo en la Francia del norte que en todo el norte peninsular - de la fórmula de arriendo del diezmo a terceros (arriendo en dinero, por tres años o múltiplos de tres, para acomodarse al ciclo agrario en las áreas del assolement trienal), planteaba serios problemas metodológicos para la conversión de las pujas en dinero a series anuales de producto agrícola deflactado por localidad o dezmería.

El mérito de los convocantes de la encuesta había sido el de proponer un método seriado para la conversión de los diezmos en dinero a producto valorado en especie, que se revelaría útil y manejable para seguir la evolución y fluctuaciones de la producción agraria, lo mismo en Galicia y en todo el norte-noroeste peninsular como en numerosas regiones de Francia. El método indirecto de análisis de la evolución del producto agrícola a partir de las pujas de arriendos diezmales en dinero - tal como hay que tratarlo en Galicia, etc. igual que en muchas regiones de Francia - lo ensayamos por primera vez en la Península en dos comunicaciones presentadas al año siguiente, en las Jornadas de 1973. Abundantes concordancias entre los trabajos más tarde reunidos avalan la plausibilidad del método. ${ }^{21}$

${ }^{21}$ Cf. Les fluctuations du produit de la dîme... Premier Congrès Nacional de l'AFHE (1969). Paris: Mouton, 1972, 396 p. [y nuestra recensión en HISPANIA, 122 (1972) 693-699]. El nuevo método de investigación diezmal fue divulgado en español el mismo año de su publicación, en esa amplia recensión en la revista Hispania, en la que resumíamos las 
De una manera más completa para Galicia lo empleamos años más tarde en un trabajo personal más amplio sobre otras 91 series de diezmos gallegos, presentado a la gran encuesta europea de 1977 sobre la fuente diezmal. En aquel mismo ambiente de las Jornadas de Metodología celebradas en 1973 en Compostela nació o cristalizó la idea de extender la primera investigación colectiva sobre el diezmo francés a otra encuesta comparatista más amplia sobre el diezmo en todos los países de la Europa católica. Idea lanzada por Labrousse, lo mismo que la anterior, fue de nuevo recogida por los dos expertos que volvieron a hacer realidad la gran encuesta en el segundo coloquio sobre los diezmos europeos, celebrado en París en 1977, preparatorio del congreso de Edimburgo de 1978. A esa encuesta contribuimos con la síntesis regional de las 91 series de diezmos gallegos, que aparece recogida en los dos volúmenes colectivos, editados luego por Goy y Le Roy Ladurie, sobre prestaciones campesinas, diezmos y movimiento de la producción agrícola en la época preindustrial. ${ }^{22}$

Las numerosas aportaciones a la gran encuesta europea de 1977 dan muestra de las posibilidades comparatistas del método francés aplicado al estudio de los diezmos peninsulares o de otros países de la Europa católica. Ese respaldo de referencia y el rigor que la técnica de la deflacción de valores expresados en dinero exige para su conversión a producto agrícola y para poder seguir a través de sus series la evolución del trend y fluctuaciones cortas de la coyuntura agraria, concede toda representatividad a las series

claves del método e inmediatamente aplicado para preparar una aportación personal a las Jornadas de 1973 sobre las primeras 15 series de diezmos gallegos. B. Barreiro presentó por su parte otra comunicación con los resultados de otras dos series diezmales, anticipo de su tesis doctoral sobre la comarca gallega del Xallas; cf. Actas 1973, Historia Moderna, III, p. 51-90 y p. 91-108. El mismo método de análisis diezmal, y del mismo origen, fue aplicado muy pronto a diezmos portugueses de la región de Braga en la tesis de Aurélio de Oliveira, A Abadia de Tibães e o seu dominio, 1630-1680 (Faculdade de Letras do Porto, 1974).

${ }^{22}$ GOY, Joseph et LE ROY LADURIE, E. - Prestations paysannes, dîmes, rente foncière et mouvement dela production agricoleàl 'époquepréindustrielle. Paris: Mouton, 1982, 2 vols., 799p. Cf. comunicación de EIRAS ROEL, A. (91 series gallegas) - Dîme et mouvement du produit agricole en Galice, 1600-1837, Vol. I, p. 341-358. Ibid. comunicación de OLIVEIRA, Aurélio de (diezmos de la región de Braga) - Dîmes et mouvement de la production agricole. Le Nord-Ouest portugais, 1626-1821, Vol. I, p. 463-477. 
gallegas y del noroeste portugués recogidas en esa obra colectiva y avala la plena adecuación del método de Le Roy Ladurie para un enfoque comparatista sobre este espacio peninsular. De este modo la encuesta de 1977 marcaba un hito que separa y divide viejo y nuevo estilo de la investigación diezmal. En 1977 como en 1973, el autor del Montaillou (1975) reinaba en la historia rural.

\section{Del documento notarial a la historia social: el segundo coloquio europeo de 1982}

En línea con lo que se esperaba de los grandes historiadores que estaban al frente de las respectivas secciones y de su impacto sobre otros entre los participantes, las Jornadas de 1973 cumplieron dejando un efecto positivo, visible en lo novedoso de las 50 aportaciones que recoge el volumen (Actas, III, 1975, 879 p.). Pero no todo podía estar en ellas y seguía existiendo campo para más. Doce años de trabajo en el recién creado archivo de protocolos notariales (1969) y las lecturas correspondientes de gran número de historiadores expertos en ese campo, nos convencieron de la necesidad de profundizar en ese terreno de amplios horizontes para la historia social y de las posibilidades de contribuir a desarrollar un nuevo sentido de la investigación sobre el documento notarial como fuente autónoma, de lo que ya existía algún precedente. Esa fue la motivación del segundo coloquio complementario de 1982 sobre la documentación notarial como fuente de la historia social.

Bajo el impulso de la regionalización de los estudios históricos, a los que esta documentación se adaptaba de modo singular, la proliferación de estudiosos de la documentación notarial y el refinamiento metódico de los estudios permitía en ese momento la convocatoria de reuniones científicas especializadas en torno a su temática y a su metodología en línea de progreso, aplicable a los archivos tal vez más ricos de Europa para el estudio de la historia social del Antiguo Régimen en los países de cultura latina: las minutas de protocolos notariales con su variada tipología de documentación. De esos encuentros específicos sobre la documentación notarial, el convocado en Compostela en 1982 era el segundo europeo, tras 
el primero celebrado en Estrasburgo en 1978, cuyos líderes se integraron en masa. ${ }^{23}$

La onda expansiva del interés por la fuente notarial y el descubrimiento de sus riquezas potenciales como fuente idónea para la historia social había venido ganando espacios en la historiografía desde los años centrales del siglo (Roland Mousnier 1945, Gaston Roupnel 1950, Louis Merle 1958, Pierre Goubert 1960). Aquellos adelantados de esa época temprana habían abierto las primeras trochas en "la selva de las minutas notariales", con sus imperfecciones y sus dificultades derivadas del volumen masivo de esa documentación, con sus trampas ocultas, sus inexactitudes y ocultaciones, pero también con sus inmensas posibilidades subyacentes. De esos precursores de la primera época dos nombres destacaban: Roland Mousnier que en fecha precoz (1945) sentó la vía del empleo del documento notarial para el estudio de las élites de notables y Pierre Goubert que en fecha menos temprana (1960) hizo uso extenso de su información al servicio de la historia social del pueblo llano; seguidos por otros, igualmente participantes en nuestro coloquio de 1982, entre ellos Abel Poitrineau (tesis, 1965), Jean Meyer (tesis, 1966), Bennassar (tesis, 1967), Jean Jacquart (tesis, 1974), Guy Cabourdin (tesis, 1977), y otros nombres ya mencionados. Todos ellos habían sido autores de grandes tesis de Estado en Francia, notables por el empleo de la documentación notarial, expertos en suma. La alta frecuencia de trabajos franceses en ese segundo coloquio celebrado en España era de nuevo un reflejo objetivo de una realidad de partida: la posición de vanguardia del modernismo francés en ese campo particular, fruto de la decisión temprana,

${ }^{23}$ Las actas de Estrasburgo están editadas por VOGLER, Bernard(ed.) - Les Actes Notariés, Source de l'Histoire Sociale XVIe.-XIXe. Siècles. Strasbourg: Librairie Istra, 1979, 342 p. Entre los participantes en el primer coloquio francés de Estrasburgo (1978) que se integraron también con sus comunicaciones o ponencias en el segundo coloquio europeo de Compostela (1982) figuran J. Meyer, G. Cabourdin, P. Ponsot, A. Poitrineau, J. Jacquart, M. Vovelle y el propio B. Vogler. En el segundo coloquio de Compostela participaron además con sus aportaciones propias Roland Mousnier, Pierre Goubert, Bartolomé Bennassar, Aldo de Magdalena (que presidieron las cuatro jornadas de trabajo de aquel intenso congreso, desarrolladas entre el 27 de septiembre y el 1 de octubre de 1982), junto a Claude Larquié (Amiens), J. P. Amalric (Toulouse), F. Brumont (Toulouse), Y. Castan (Toulouse), J. Marcadé (Poitiers), J. Fayard (Dijon), J. P. Le Flem (Sorbona), M. A. Romani (Milán), J.G. da Silva (Niza) e I.M. Vaquinhas (Coimbra), entre muchos otros autores de comunicaciones españoles o no. 
de la continuidad sostenida y del amplio número de sus cultivadores. Del mismo modo que una centuria antes la erudición alemana se había impuesto por el número y calidad de sus filólogos volcados sobre los textos antiguos, en este campo particular se imponían ahora los más asiduos.

La metodología exhibida en los trabajos de las décadas de los sesenta y setenta venía ya anunciando la puesta en valor del documento notarial como fuente serializada en lugar de seguir tratándolo como documento singular o único - al modo como pueden serlo el testamento de un prócer o un contrato de cantería para la construcción del transparente de la catedral de Toledo, etc. - junto a sus inmensas posibilidades latentes para la historia social, derivadas precisamente de su masa y volumen y del carácter repetitivo y "típico" de la mayor parte de sus escrituras; así como de su extensión global a diversos momentos y medios, de su ventilación por tiempos y por grupos sociales, que lo hacían idóneo para un tratamiento comparativo en el espacio y en el tiempo... o en el espacio social de los diversos grupos.

En el primer coloquio francés de 1978 en Estrasburgo esa línea metodológica se confirmó y en el segundo coloquio europeo de 1982 en Compostela se consolidó, además de incorporar algunas ampliaciones interesantes que enunciamos en fórmula abreviada, sin desarrollarlas aquí en detalle. A saber, confirmación del método cuantitativo a través del corte tipológico masivo y serial; valor autónomo de cada tipo de escritura por sí mismas (ventas de tierras, arriendos, etc.), polivalencia de algunas de ellas (el testamento, la dote) y valorización de nuevas tipologías menos frecuentadas (inventarios urbanos, papeles de sucesión, poderes, concordias, etc.); profundización en la problemática crítica sobre la fuente y sus sesgos ocultos (representatividad, veracidad, adecuación, suficiencia); y todavía, incorporación de la documentación notarial al encuadre coyuntural (recuperación de la coyuntura tanto económica como social) - la aportación más novedosa de ese segundo coloquio -, mediante la comparación en el tiempo de las escrituras de un mismo conjunto y naturaleza (dotes, ventas, préstamos, ganados) y de un mismo grupo social en diferentes momentos. ${ }^{24}$

\footnotetext{
${ }^{24}$ Para el desarrollo de las nociones de corte tipológico, encuadre coyuntural, método del año-testigo, etc. y otras que sólo podemos mencionar escuetamente aquí, remitimos a nuestra introducción a La Documentación Notarial y la Historia, 1984, vol. I, p. 13-30.
} 
Los 50 trabajos individuales presentados en las cuatro jornadas de aquel intenso y nutrido segundo congreso, que se desarrollaron entre el 27 de septiembre y el 1 de octubre de 1982, y que figuran recogidos en sus dos volúmenes de Actas (1984), ofrecen los resultados de investigaciones monográficas sobre la diversa tipología de las fuentes notariales, entre las que prevalecen por su riqueza de información algunos tipos de escrituras predilectos de los especialistas del género. Así, los contratos matrimoniales para el estudio de las relaciones entre linajes, de las alianzas entre los grupos y de las jerarquías sociales en los niveles superior y medio de la sociedad (la fuente predilecta de Roland Mousnier y de sus discípulos allí presentes, entre ellos Janine Fayard); las constituciones de dote y cartas de pago de dote o quittances de dot para un uso equivalente en el medio campesino aunque no sólo (la fuente predilecta de Abel Poitrineau, entre otros investigadores allí presentes); los inventarios post mortem para el estudio del utillaje agrícola y del capital de las economías domésticas en el medio campesino igualmente (la fuente predilecta de Hoskins o de Pierre Goubert y de los ruralistas gallegos allí presentes); el testamento para el estudio de las estrategias familiares (el empleo predilecto de Bernard Vogler) y de las actitudes del hombre ante sus postrimerías (el empleo predilecto de Michel Vovelle y de Domingo González Lopo, entre los allí presentes). Los contratos de arrendamiento idóneos para el estudio de los sistemas agrarios y de la estructura de la propiedad. Las constituciones de renta (censos consignativos) y reconocimientos de préstamo (en este caso usados por Pierre Goubert), idóneos para el estudio del endeudamiento popular y los efectos negativos de la coyuntura en diferentes medios sociales, mediante su empleo seriado. Las compraventas de propiedad para el estudio de la desmembración de la propiedad parcelaria del campesinado pequeño y medio, entre otros sectores sociales (la fuente predilecta de Guy Cabourdin, combinada con la anterior, para el estudio de la coyuntura social y de los efectos de la crisis agraria en medio rural o urbano). ${ }^{25}$

${ }^{25}$ Para el encuentro complementario de 1982 sobre protocolos notariales e historia social, las ponencias introductorias fueron encomendadas a otros tantos autores de grandes tesis francesas, ejemplares por múltiples conceptos, entre ellos el uso masivo, seriado y conceptualmente razonado de la documentación notarial; tal como eran la tesis sobre la nobleza bretona del siglo XVIII (cf. MEYER, Jean - L'apport notarial à l'histoire sociale 
En cuanto a los resultados internos del segundo coloquio de 1982, puede afirmarse que supuso la incorporación plena de los investigadores españoles a las mismas temáticas y a la misma metodología del empleo seriado de la fuente notarial para el aprovechamiento de todas sus potencialidades de empleo masivo. Más todavía, el estudio sincrónico fue trascendido en busca del cambio diacrónico y de la coyuntura social, mediante el recurso al análisis comparativo de valores homogéneos en momentos diferentes del tiempo. El cambio temático va acompañado también de novedades en las técnicas de aproximación a la masa de las fuentes notariales: la búsqueda selectiva de escrituras aisladas cede lugar a las técnicas aleatorias de muestreo, a la selección orientada basada en el criterio tipológico, al despojo sistemático de las actas de uno o varios escribanos locales, o a la vía de aproximación total por cortes cronológicos de un amplio número de escribanos (método del año-testigo). En un plano general, por el número y calidad de los expertos allí congregados, por la ampliación del empleo de la fuente a los aspectos inmateriales de la cultura y las mentalidades colectivas y por la inclinación al método comparado - sobre grupos homogéneos y grupos diferentes u opuestos en la escala social - ambos coloquios sucesivos (realizados a distancia de cuatro años solamente) marcaron a nuestro entender líneas de futuro en la investigación sobre la fuente notarial a escala europea, un inicio de apertura al método comparado a través de la regionalización de los estudios.

de l'Europe moderne, I, 33-74); la tesis sobre la venalidad de los oficios en la Francia del Antiguo Régimen (cf. MOUSNIER, Roland - Les structures sociales de Paris à la veille de la Révolution, I, 75-92); la tesis sobre la vida rural en la cuenca de París (a saber Ile-de-France, cf. JACQUART, Jean - Sources notariales et histoire rurale, I, p. 245-268); la tesis sobre la vida rural en Auvernia (cf. POITRINEAU, Abel - Niveaux de vie et de fortune d'après les minutes notariales: les ruraux auvergnats, I, p. 269-285) y la tesis sobre piedad barroca y descristianización en Provenza (cf. VOVELLE, Michel - Minutes notariales et histoire des cultures et des mentalités, II, p. 9-27). Para la sección dedicada al empleo de los protocolos notariales en la historia mercantil, industrial y del crédito, la ponencia introductoria fue confiada a otro español discípulo de Braudel, autor de sólidas monografías sobre las relaciones mercantiles con Amberes (cf. VÁZQUEZ DE PRADA, Valentín - Protocolos notariales e Historia Económica: crédito, comercio e industria, II, p. 189-218. Todas las ponencias y comunicaciones del coloquio de 1982, public. in La Documentación Notarial y la Historia. Actas del II Coloquio de Metodología Histórica Aplicada. Universidad de Santiago de Compostela, 1984, 2 vols. 


\section{Propuesta, a modo de reflexión final. ¿Hacia una historia comparada?}

Atraemos aquí la atención del historiador actual sobre los encuentros multidisciplinares celebrados en 1973 y 1982 a modo de vade-mecum de la renovación metodológica de la segunda generación de Annales en sus tres vectores principales: $1 \%$ ampliación temática (nuevos aspectos, nuevos problemas, nuevas propuestas, nuevas encuestas); $2 \%$ nuevas fuentes no intencionales y todavía « durmientes », como queda desarrollado más atrás; y $3 \%$ renovación de los métodos de análisis con una moderada aproximación a los procedimientos de trabajo usados en otras ciencias sociales, o mediante la aplicación de técnicas estadísticas (siquiera elementales) a los megadocumentos fiscales, catastrales, notariales y otras masas de datos brutos. Una base común a toda esa variedad de enfoques reposa en el recurso al tratamiento cuantitativo y comparativo de todos los factores que permiten ser cuantificados en el discurso histórico (al menos en el dominio de lo económico y lo social, menos tal vez en lo político y cultural) para hacerlos evaluables y comparables en el espacio y en el tiempo. El salario, la dieta, la producción por cabeza o por fuego, el precio del pan, etc. son valores evaluables y su fluctuación en el tiempo es un ingrediente necesario de la historia social de la población en abstracto, o de los grupos sociales discrecionalmente considerados en concreto. Se habla de una cuantificación inteligente y operacional, de y para historiadores (la de Labrousse valdría a la perfección), sencilla y sin artificios en todo caso; por supuesto, sin ese género de adoración de las máquinas prodigiosas y las ecuaciones impenetrables (como las de la Cliometría de Robert Fogel) que se desencadenaría desde los U.S.A. en la siguiente década.

Los múltiples incentivos de renovación que nos han llegado del exterior a los historiadores peninsulares en el último tercio del pasado siglo, de los que aquí sólo se han mostrado unos pocos aunque muy importantes ejemplos, nos han revelado, a la vez, que no existe historia social fuera del marco regional (o local, pero éste último sólo cabe entenderlo dentro de su marco de referencia inmediatamente superior, la síntesis regional o más amplia, so pena de diluirlo en la polvareda de los évenements de imposible registro) y que a su vez la historia regional carece de sentido último si no es integrable 
en unidades de civilización más amplias. En historia social el regional es el único marco de estudio que reúne las tres propiedades necesarias de resultar a la vez: abarcable, suficiente e integrable.

Es abarcable porque la cultura regional reúne unidad de caracteres entre sus diferentes partes, susceptibles por lo mismo de reducción a la unidad. Es suficiente porque cada cultura regional posee su propia lógica interna, fruto de la experiencia de los siglos, que autoriza a razonar los componentes del sistema. Es integrable porque permite observar las afinidades y diferencias que identifican a un conjunto particular dentro de un hecho de civilización o fenómeno general; sea en este caso la síntesis histórica construida a lo largo del último milenio (el marco del Estado-Nación) o el substrato anterior preexistente que es el verdadero hecho de civilización de larga duración (la civilización europea occidental en alguna de sus variantes).

El marco de referencia último para la historia social de los pueblos peninsulares es en primera instancia el que forman ellos mismos, por separado o conjuntamente, y en última instancia la civilización europea occidental a la que pertenecen desde la época romana del Bajo Imperio. Los nombres de San Benito de Nursia o de San Bernardo de Claraval tienen seguramente mucho que decir en la formación de ese hecho de civilización común. Cuanto más avanzan las investigaciones monográficas de historia social más similitudes se encuentran por debajo o al lado de las diferencias entre pueblos y costumbres. El medio que el historiador tiene para situar en la perspectiva que les corresponde las similitudes y diferencias entre las unidades de estudio de ese conjunto es la historia comparada.

El paso de cultura particular a hecho de civilización sólo se logra a través de la historia comparada. Las páginas que preceden contienen algunos ejemplos o posibilidades de comparatismo, aunque no profundicen en la ortodoxia del método comparado. Sin salir sólo de este limitado contorno - aunque pudiera haber ejemplos mejores - historia comparada es apreciar que la evolución del poder adquisitivo del salario en el siglo XVIII no difiere mucho entre la generalidad de Amiens y Santiago de Compostela, lo que invita a considerar alguna causa común (demográfica). Historia comparada es también apreciar las fechas comunes y coincidentes de las grandes crisis agrarias de la pequeña edad glaciar en la Francia del Norte y en Galicia o el centro-norte de Portugal; o los efectos comunes del interciclo sobre 
los precios y curvas diezmales en esos mismos espacios, lo que supone igualmente una causa común (climática). Como lo es el observar que la tasa de reemplazo generacional del Auneuil del XVII puede ser más afín a la de Tierra de Campos que a la del Salnés o a la de Guimarâes (lo que se comprende perfectamente); mientras que la capacidad de formación de excedentes (compulsivos) puede ser más afín entre el campesinado del Salnés y el del Beauvaisis. En la encuesta internacional de 1977 sobre el diezmo la síntesis de los resultados de varios países aprecia no pocas afinidades y también algunas diferencias, una vez agrupados por sectores. Esas afinidades y diferencias requieren sin duda ser explicadas. De la observación de los hechos comunes a la elevación a las causas comunes hay un gran paso, eminentemente histórico, en el que entra en juego la elasticidad y la formación del historiador.

\section{Referencias}

Actas de las I Jornadas de Metodología Histórica Aplicada. III. Historia Moderna. Universidad de Santiago de Compostela, 1973 [1975], vol. III, $879 \mathrm{p}$.

Actas del II Coloquio de Metodología Histórica Aplicada. La documentación notarial y la Historia. Universidad de Santiago de Compostela, 1982 [1984], 2 vols. 460 y 446 p.

AA. VV. - Congreso de Historia Rural. Siglos XV al XIX. Coloquio de la Casa de Velázquez, octubre 1981. Madrid: Universidad Complutense, 1984, 870 p. (comunic. p. 393-413 y otras).

BAEHREL, R.- Une croissance: La Basse Provence rurale (fin du XVIe. siécle-1789). Paris: SEVPEN, 1961, 2 vols.

BARREIRO MALLÓN, Baudilio - La Jurisdicción de Xallas en el siglo XVIII. Población, sociedad y economía. Secretariado de Publicaciones de la Universidad de Santiago, 1973 (2 ${ }^{\mathrm{a}}$ ed. 1978), 698 p.

BENNASSAR, B. - Recherches sur les grandes épidemies dans le nord de l'Espagne à la fin du XVIe. siècle. Paris: SEVPEN, 1969, 192 p. [Recensión de A. Domínguez Ortiz en HISPANIA. 112 (1969) 453-455]. EIRAS ROEL, A. (et al.) - Las fuentes y los métodos. 15 trabajos de historia cuantitativa serial de Galicia. Universidad de Santiago, 1977, 372 p. 
- La historia social de Galicia en sus fuentes de protocolos. Universidad de Santiago, 1981, 564 p. [Introd., "Tipología documental de los protocolos gallegos", p. 21-113].

EIRAS ROEL, A. - Estudios sobre agricultura y población en la España Moderna. Universidad de Santiago, 1990, 197 p.

- La metodología de la investigación histórica sobre documentación notarial: introducción general in La Documentación Notarial y la Historia. Actas del II Coloquio de Metodología Histórica Aplicada, Universidad de Santiago, 1984, I, p. 13-30.

- La población de Galicia, 1700-1860. Santiago: Fundación Caixa Galicia, 1996, $811 \mathrm{p}$.

FAUVE-CHAMOUX, A. - Évolution agraire et croissance démographique. Préface de A. Eiras Roel. Liège: Ordina Editions, 1987, 389 p. (Rapport sobre España, p. 113-123).

GODINHO, Vitorino Magalhães - Création et dynamisme économique du monde atlantique. Annales E.S.C. (1950) 32-36.

- Prix et monnaies au Portugal, 1750-1850. Paris: EPHE, 1955.

- L'économie de l'empire portugais aux XVe. et XVIe. siècles. L'or et le poivre. Paris: Sorbonne, 1958 (public. SEVPEN, 1969).

GOUBERT, Pierre-Beauvais et le Beauvaisis de 1600 à 1730. Contribution à l'histoire sociale de la France du XVIIe. siècle. Paris: EHESS, 1960 (2a ed. 1982, 2 vols., 772 p.).

- Cent Mille Provinciaux au XVIIe siècle. Paris: Flammarion, 1968, 439 p. [Recensión en HISPANIA. 121 (1972) 490-495].

- Clio parmi les Hommes. Paris: Mouton, 1976, 310 p.

GOY, J. et LE ROY LADURIE, E. - Les fluctuations du produit de la dîme. Conjoncture décimale et domaniale de la fin du Moyen Age au XVIIIe. siecle. Paris: Mouton, 1972, 396 p. [Recensión en HISPANIA. 122 (1972) 693-699].

- Prestations paysannes, dîmes, rente foncière et movement de la production agricole à l'époque préindustrielle. Paris: Mouton, 1982, 2 vols., $799 \mathrm{p}$.

KULA, Witold - Théorie économique du Système Féodal. Pour un modèle de l'économie polonaise, 16e.-18e. siècles. Paris: Mouton, 1970, 173 p. [Recensión en HISPANIA, 119 (1971) 659-671]. 
LABROUSSE, Ernest - Esquisse du mouvement des prix et des revenus en France au XVIIIe. siècle. Paris: Dalloz, 1933 (2 ${ }^{\mathrm{a}}$ ed. 1984, 2 vols.).

- La crise de l'économie française à la fin de l'Ancien Régime et à la veille de la Révolution. Paris: PUF, 1944.

- Fluctuaciones económicas e Historia Social. Madrid: Tecnos, 1962, $478 \mathrm{p}$.

LABROUSSE, Ernest; ROMANO, Ruggiero et DREYFUS, F-G. - Le prix du froment en France au temps de la monnaie stable (1726-1913). Paris: SEVPEN, 1970, 342 p. [Recensión en HISPANIA. 120 (1972) 227-231]. LE ROY LADURIE, E. - "Voies nouvelles pour l'histoire rurale (XVIe. -XVIIIe. siècles)". Études Rurales, 13-14, 1964, 79-95.

- Les paysans de Languedoc. Paris: SEVPEN, 1966, 2 vols. 745 p. [2 $2^{\mathrm{a}}$ ed. Flammarion, 1969].

— Histoire du climat depuis l'an mil. Paris: Flammarion, 1967, 366 p.

MAGALHÃES, Joquim Romero de - O Algarve económico, 1600-1773. Lisboa: Estampa, 1993.

MAGDALENA, Aldo de - Prezzi e Mercedi a Milano dal 1701 al 1860. Banca Commerciale Italiana, 1974, 2 vols.

MAURO, Fréderic - Le Portugal et l'Atlantique au XVIIe. siècle (1570-1670). Paris: SEVPEN, 1960.

MEUVRET, J. - Études d'histoire économique. Paris: A. Colin, 1971.

MOUSNIER, Roland - La plume, la faucille et le marteau. Paris: P.U.F., 1970, 399 p.

- Recherches sur les structures sociales parisiennes en 1634, 1635, 1636 in Actas de Metodología Histórica Aplicada. III. Historia Moderna, 1973, p. 505-526.

- Les structures sociales en Paris à la veille de la Révolution (1784) in Actas del II Coloquio de Metodología Histórica Aplicada, I, 1982, p. 75-92.

PÉREZ GARCÍA, José Manuel - Un modelo de sociedad rural en la Galicia costera. La península del Salnés. Universidad de Santiago de Compostela, 1979, 416 p., tablas y apéndices.

POUSSOU, Jean-Pierre - Bordeaux et le Sud-Ouest au XVIIIe. Siècle. Croissance économique et attraction urbaine. Tesis EHESS. Paris, 1983. 
QUINTÁNS VÁZQUEZ, Maria Carmen - El dominio de San Martín Pinario ante la Desamortización. Rentas de la Abadía. Universidad de Santiago, 1972, 139 p.: tablas estadísticas.

RAU, Virginia - Large-scale agricultural enterprise in post-medieval Portugal in Première Conférence Internationale d'Histoire Économique. Stockholm, 1960; Paris: Mouton, 1960, p. 425-435.

- Feitores et feitorías no comercio internacional portugués do seculo XVI in Troisième Conférence Internationale d'Histoire Économique. Munich 1965. Paris: Mouton, 1968 (Reimpr. Lisboa, Brotéria, 66 p.).

REY CASTELAO, Ofelia - Aproximación a la historia rural en la comarca de La Ulla (siglos XVII y XVIII). Universidad de Santiago, 1981, 309 p. RODRÍGUEZ FERREIRO, H. - La Tierra de Trasdeza, una economía rural antigua. Universidad de Santiago, 1979, 165 p., tablas estadísticas.

- Economía y población rural en la Galicia atlántica. La jurisdicción del Morrazo en los siglos XVII y XVIII. Universidad de Santiago, 1981. (Existe edición póstuma del año 2003: Diputación de Pontevedra, Servicio de Publicaciones, 3 vols.).

SAAVEDRA FERNÁNDEZ, P. - Economía rural antigua en la montaña lucense. El concejo de Burón. Universidad de Santiago, 1979, 147 p., tablas estadísticas.

- Economía, política y sociedad en Galicia: la provincia de Mondoñedo, 1480-1830. Xunta de Galicia, 1985, 697 p.

SALOMON, Noël - La Campagne de la Nouvelle Castille à la fin du XVIe. siècle, d'après les "Relaciones Topográficas”. Paris: SEVPEN, 1964.

SILBERT, Albert - Le Portugal méditérranéen à la fin de l'Ancien Régime, XVIIIe.-début du XIXe. siècle. Paris: SEVPEN, 1966, 2 vols.

SILVA, José Gentil da - Capitaux et marchandises. Échanges et finances entre le XVIe. et le XVIIe. siècle. Annales E.S.C. 1957, p. 287-300.

- Stratégie des affaires à Lisbonne entre 1595 et 1607. Paris: SEVPEN, 1956.

- Marchandises et finances. Lettres de Lisbonne, 1563-1578. Paris: SEVPEN, 1959, 2 vols.

- La part des salaires dans le revenu nacional comme question historique in Troisième Conférence Internationale d'Histoire Économique. Munich, 1965; Paris: Mouton, 1968, 621-646. 